\title{
Simultaneous Shape and Size Optimization of Double-layer Grids with Nonlinear Behavior
}

\author{
Ali Kaveh $^{1 *}$, Mehran Moradveisi $^{2}$ \\ 1 School of Civil Engineering, Iran University of Science and Technology, Narmak, Tehran P.O. Box 16846-13114, Iran \\ ${ }^{2}$ Road, Housing and Urban Development Research Center, Tehran P.O. Box 13145-1696, Iran \\ * Corresponding author, e-mail: alikaveh@iust.ac.ir
}

Received: 12 May 2020, Accepted: 11 June 2020, Published online: 29 July 2020

\begin{abstract}
The main aim of this paper is to present a new solution for simultaneous shape and size optimization of double-layer grids. In order to find the optimum design, Enhanced Colliding Bodies Optimization method is applied to the optimum design of the most common examples of double-layer grids, while both material and geometrical nonlinearity are taken into account. The small and big sizes of span length are considered for each type of square grids. The algorithm gets the minimum weight grid by finding the best nodal location in z-direction (height of the structure) and the suitable selection from the list of tube sections available in American Institute of Steel Construction Load and Resistance Factor Design, simultaneously. All examples are optimized with strength and displacement constraints. The numerical results demonstrate the efficiency and robustness of the presented method for solving real-world practical double-layer grids.
\end{abstract}

Keywords

shape-size optimization, optimum height, double-layer grids, nonlinear behavior, enhanced colliding bodies optimization

\section{Introduction}

Spatial structures became well-known not only because of their aesthetically pleasing layout and greater reserves of strength compared to conventional structures but also because of their simple and fast construction. The continuous repetition of the basic component reduces production time and cost; assembly on site is quick and easy and the replacement of damaged elements and future expansion of the construction presents no real problem. Space trusses are three-dimensional structures that are highly statically indeterminate, creating an optimum distribution of stress that uses less material with greater rigidity and load-carrying capacity. Double-layer grids are well-suited for covering assembly halls, exhibition pavilions, swimming pools, churches, bridge decks, and many different types of industrial buildings where large unobstructed areas are needed. Double-layer grids are successfully built at a lower expense than conventional comparable systems, offering additional benefits at the same time, such as greater rigidity, ease of construction and the ability to cover larger areas. These kinds of grids can be considered as logical extensions of single-layer grid frameworks, consisting of two or more sets of parallel beams that intersect at right or oblique angles and are loaded by forces perpendicular to the plane of the framework. For clear spans of up to $10 \mathrm{~m}$, single-layer grids are used. Double layer grids are more suitable for larger spans and provide a cost-effective solution for spans up to $100 \mathrm{~m}$. Double-layer grids consist of two plane grids (which are not necessarily of the same layout) comprising the top and bottom layers, parallel to each other, linked by vertical or inclined "web" diagonal members. Single-layer grids are mostly under the action of flexural moments, while double-layer grid component members are almost exclusively under the action of axial forces. The elimination of bending moments results in the complete use of the strength of all the elements $[1,2]$. Double-layer grids have a larger number of structural elements and the use of optimization techniques has a major impact on the economy and the effective design of such systems [3]. Recently added meta-heuristic algorithms have been developed for the optimal design of real-life systems and models with complex configurations and a large number of elements [4]. It is necessary to determine the depth between the top and bottom layers before any work can proceed on the analysis of a double-layer grid. 
While this parameter appears sufficiently simple to determine, it will still play an important role in the roof design economy. This parameter is determined by many factors, such as the form of double-layer grid, the distance between the supports, the cladding of the roof and the proprietary system used. The depth is standardized for some of the proprietary systems. The depth of double-layer grids is usually determined by practical experience. Figures on this parameter are suggested in some of the articles and handbooks and one may consider the variation to be quite broad. The span-depth ratio, for instance, ranges between 12.5 and 25 , or even more. The span-depth ratio is defined by span in the earlier edition of the Specifications for the Design and Construction of Space Trusses published in China [5]. These figures have been obtained by analyzing the parameters used in many design projects. A double-layer grid design handbook also provides graphs for determining the upper and lower bounds of the dimensions and depth of the module [6]. The optimum values are in good agreement with those acquired from experience for short and medium spans. It is remarkable that the span-depth ratio should decline with the span, yet there is a growing inclination from experience, which gives unreasonably large values over long spans. In the design, there are practically unlimited possibilities for geometry selection. Thus, it is best to determine this parameter by structural optimization. Some studies are carried out for double layer grids in the case of shape and size optimization. For example, Kaveh and Ilchi Ghazaan [7] applied CBO, ECBO, VPS, MDVC-UVPS for size optimization of large-scale double-layer grids. Ermopoulos achieved the optimum height of double-layer grids at the stage of preliminary design [8]. Kaveh and Talatahari [9] applied the BB-BC algorithm for the size optimization of space trusses. Kaveh et al. [10] examined different algorithms in the case of shape and size optimization of double-layer grids. Kaveh and Moradveisi [11] applied CBO and ECBO for shape and size optimization of two commonly used double-layer grids. Kaveh and Bakhshpoori [12] presented an effective algorithm and solved benchmark structural optimization problems. Kazemzadeh Azad et al. [13] used a guided stochastic search technique for discrete sizing optimization of steel trusses. Kaveh and Moradveisi [14] applied nonlinear effects in the optimal design of double-layer grids. Kaveh et al. [15] performed the PRSSOA algorithm for the size optimization of a 1016-bar double-layer grids, but a more comprehensive study of the problem of simultaneous shape and size optimization is still required. The objective of the size optimization of skeletal structures is to minimize structure weight $W$ by finding the optimal cross-sectional areas $A i$ of members. The aim of shape optimization of skeletal structures is to find the best state of nodal coordinates to minimize the structure weight $W$, in this process, the $\mathrm{x}$ and y coordinates of the joints will remain constant and the $\mathrm{z}$ coordinate of the nodes is varied. In previous studies finding the best height of the structure (shape optimization) needed numerous independent Runs (for each value of the height design vector one independent Run was needed, then all results were compared to find the best height of the structure) [10, 11]. This method is highly time-consuming especially when nonlinearity is taken into account, while in this paper this process is carried out by algorithm in just one independent Run and all constraints exerted on both problems of shape and size optimization must be satisfied, simultaneously. Every example is solved 5 times independently due to the stochastic essence of the algorithm. If the processing time is measured in terms of CPU time of a PC with the processor of Intel ${ }^{\circledR}$ Core $^{\mathrm{TM}}$ i7-3612 QM @ 2.1 GHz equipped with $6 \mathrm{GBs}$ of RAM, this presented method decreases the computational time from nearly 50 days non-stop Runs to 1 day and 9 hours for solving one complete example of the optimal design of large-scale nonlinear structures. This research concerned with economical comparison of two widely used double-layer grid configurations, namely diagonal on diagonal grid and two-way on two-way grid. At first two double-layer grids of different span sizes are investigated to verify the robustness of the present technique in finding optimal solutions for these kinds of design problems using different optimization algorithms. Then six numerical examples of span sizes of $12 \mathrm{~m} \times 12 \mathrm{~m}$ and $30 \mathrm{~m} \times 30 \mathrm{~m}$ are considered as small and big size grids. These grids are optimized to challenge the ECBO in designing real-world double-layer grids including their nonlinear behavior.

The paper is structured as follows: Section 2 recalls the optimal design of double-layer grids. Section 3 describes the optimization algorithm. Section 4 examines the proposed method of simultaneous shape and size optimization versus the previous methods of shape and size optimization using different optimization algorithms. Nonlinear behavior and structural models are discussed in Section 5 and Section 6, respectively. Optimization results are presented and discussed in Section 7. Finally, the last section concludes the paper. 
Table 1 The steel pipe sections taken from AISC-LRFD

\begin{tabular}{|c|c|c|c|c|c|c|c|}
\hline & Type & Nominal diameter (in) & Weight per ft (lb) & Area $\left(\mathrm{in}^{2}\right)$ & $\mathrm{I}\left(\mathrm{in}^{4}\right)$ & Gyration radius (in) & $\mathrm{J}\left(\mathrm{in}^{4}\right)$ \\
\hline 1 & ST & $1 / 2$ & 0.85 & 0.25 & 0.017 & 0.261 & 0.034 \\
\hline 2 & EST & $1 / 2$ & 1.09 & 0.32 & 0.02 & 0.25 & 0.04 \\
\hline 3 & ST & $3 / 4$ & 1.13 & 0.333 & 0.037 & 0.334 & 0.074 \\
\hline 4 & EST & $3 / 4$ & 1.47 & 0.433 & 0.045 & 0.321 & 0.09 \\
\hline 5 & $\mathrm{ST}$ & 1 & 1.68 & 0.494 & 0.087 & 0.421 & 0.175 \\
\hline 6 & EST & 1 & 2.17 & 0.639 & 0.106 & 0.407 & 0.211 \\
\hline 7 & ST & $1 \frac{1 / 4}{4}$ & 2.27 & 0.669 & 0.195 & 0.54 & 0.389 \\
\hline 8 & $\mathrm{ST}$ & $1 \frac{1}{2}$ & 2.72 & 0.799 & 0.31 & 0.623 & 0.62 \\
\hline 9 & EST & $1 \frac{1 / 4}{4}$ & 3.00 & 0.881 & 0.242 & 0.524 & 0.484 \\
\hline 10 & $\mathrm{ST}$ & 2 & 3.65 & 1.07 & 0.666 & 0.787 & 1.33 \\
\hline 11 & EST & $1 \frac{1}{2}$ & 3.63 & 1.07 & 0.391 & 0.605 & 0.782 \\
\hline 12 & EST & 2 & 5.02 & 1.48 & 0.868 & 0.766 & 1.74 \\
\hline 13 & $\mathrm{ST}$ & $21 / 2$ & 5.79 & 1.7 & 1.53 & 0.947 & 3.06 \\
\hline 14 & $\mathrm{ST}$ & 3 & 7.58 & 2.23 & 3.02 & 1.16 & 6.03 \\
\hline 15 & EST & $21 / 2$ & 7.66 & 2.25 & 1.92 & 0.924 & 3.85 \\
\hline 16 & DEST & 2 & 9.03 & 2.66 & 1.31 & 0.703 & 2.62 \\
\hline 17 & ST & $31 / 2$ & 9.11 & 2.68 & 4.79 & 1.34 & 9.58 \\
\hline 18 & EST & 3 & 10.25 & 3.02 & 3.89 & 1.14 & 8.13 \\
\hline 19 & ST & 4 & 10.79 & 3.17 & 7.23 & 1.51 & 14.5 \\
\hline 20 & EST & $31 / 2$ & 12.50 & 3.68 & 6.28 & 1.31 & 12.6 \\
\hline 21 & DEST & $21 / 2$ & 13.69 & 4.03 & 2.87 & 0.844 & 5.74 \\
\hline 22 & $\mathrm{ST}$ & 5 & 14.62 & 4.3 & 15.2 & 1.88 & 30.3 \\
\hline 23 & EST & 4 & 14.98 & 4.41 & 9.61 & 1.48 & 19.2 \\
\hline 24 & DEST & 3 & 18.58 & 5.47 & 5.99 & 1.05 & 12 \\
\hline 25 & $\mathrm{ST}$ & 6 & 18.97 & 5.58 & 28.1 & 2.25 & 56.3 \\
\hline 26 & EST & 5 & 20.78 & 6.11 & 20.7 & 1.84 & 41.3 \\
\hline 27 & DEST & 4 & 27.54 & 8.1 & 15.3 & 1.37 & 30.6 \\
\hline 28 & $\mathrm{ST}$ & 8 & 28.55 & 8.4 & 72.5 & 2.94 & 145 \\
\hline 29 & EST & 6 & 28.57 & 8.4 & 40.5 & 2.19 & 81 \\
\hline 30 & DEST & 5 & 38.59 & 11.3 & 33.6 & 1.72 & 67.3 \\
\hline 31 & ST & 10 & 40.48 & 11.9 & 161 & 3.67 & 321 \\
\hline 32 & EST & 8 & 43.39 & 12.8 & 106 & 2.88 & 211 \\
\hline 33 & ST & 12 & 49.56 & 14.6 & 279 & 4.38 & 559 \\
\hline 34 & DEST & 6 & 53.16 & 15.6 & 66.3 & 2.06 & 133 \\
\hline 35 & EST & 10 & 54.74 & 16.1 & 212 & 3.63 & 424 \\
\hline 36 & EST & 12 & 65.42 & 19.2 & 362 & 4.33 & 723 \\
\hline 37 & DEST & 8 & 72.42 & 21.3 & 162 & 2.76 & 324 \\
\hline
\end{tabular}

$\mathrm{ST}=$ Standard weight, $\mathrm{EST}=$ Extra strong, DEST $=$ Double extra strong

\section{Optimal design of double-layer grids}

The design variables are the depth between the top and bottom layers and the cross-sectional areas of the bar elements. The permissible cross-sections are selected from the list of steel pipe sections from AISC-LRFD [16]. These pipe sections are shown in Table 1. The ST, EST, and DEST abbreviations stand for standard weight, extra strong, and double-extra strong, respectively. The purpose of the grid optimization problem is to find a set of design variables that result in a minimum double-layer grid weight while satisfying certain constraints. This can be defined as: 
Find $\{X\}=\left[x_{1}, x_{2}, x_{3}, \ldots, x_{n g}\right], h$

$x_{i} \in D=\left\{d_{1}, d_{2}, d_{3}, \ldots, d_{37}\right\}$

$h_{i} \in H=\left\{h_{1}, h_{2}, h_{3}, \ldots, h_{37}\right\}$

To minimize $W(\{X\})=\sum_{i=1}^{n g} x_{i} \sum_{j=1}^{n m(i)} \rho_{j} \cdot L_{j}$.

where $\{X\}$ is the vector containing the design variables for size optimization; $n g$ is the number of design groups; $D$ is the set of cross-sectional areas available for groups according to Table $1 ; h$ is the height of the double-layer grid which is known as the only shape variable; $H$ is the height design vector which contains the discrete variables for the purpose of practical design; $W(\{X\})$ indicates the weight of the structure; $n m(i)$ is the number of members for the $i$ th group; $\rho_{j}$ and $L_{j}$ signify the density of the material and the length for the $j$ th member of the $i$ th group, respectively;

The constraint conditions for grid structures are described briefly in the following:

Displacement constraints:

$\delta^{i} \leq \delta^{\max }, i=1,2, \ldots, n n$.

Tension member constraints:

$$
P_{u} \leq P_{r}: \quad P_{r}=\min \left\{\begin{array}{ll}
F_{y} \cdot A_{g} \cdot \varnothing_{t} & \varnothing_{t}=0.9 \\
F_{u} \cdot A_{e} \cdot \varnothing_{t} & \varnothing_{t}=0.75
\end{array} .\right.
$$

Compression member constraints:

$$
\begin{aligned}
& P_{u} \leq P_{r} ; \quad P_{r}=\varnothing_{c} \cdot F_{c r} \cdot A_{g} ; \quad \varnothing_{c}=0.85 \\
& F_{c r}=\min \left\{\begin{array}{l}
\left(0.658^{F_{y} / F_{e}}\right) F_{y}, \frac{K L}{r} \leq 4.71 \sqrt{E / F_{y}} \\
0.877 F_{e}
\end{array}, \begin{array}{rl}
\frac{K L}{r}>4.71 \sqrt{E / F_{y}}
\end{array}, F_{e}^{2} E /(K L / r)^{2} .\right.
\end{aligned}
$$

Slenderness ratio constraints:

$$
\begin{array}{ll}
\lambda_{c}=K L / r \leq 200 & \text { for compression members } \\
\lambda_{t}=K L / r \leq 300 & \text { for tension members }
\end{array}
$$

Where $\delta^{i}$ and $\delta_{i}^{\max }$ are the displacement and allowable displacement for the $i$ th node; $n n$ is the number of nodes; $P_{u}$ is the required strength (tension or compression); $P_{r}$ is the nominal axial strength (tension or compression); $F_{y}$ and $F_{u}$ are the minimum specified yield stress and minimum specified tensile strength, respectively; $F_{c r}$ is the critical stress; $A_{g}$ and $A_{e}$ are the gross cross-sectional and the effective net cross-sectional area of a member, respectively. $K$ is effective length factor taken equal to $1 ; L$ is the length of member; and $r$ is the radius of gyration. $\varnothing_{t}$ and $\varnothing_{c}$ are the resistance factors for tension and compression members, respectively.

For the purpose of handling the constraints, the penalty approach is used. In this method, the objective of the optimization is redefined by introducing the cost function as:

$$
\begin{aligned}
& f_{\text {cost }}(\{X\})=\left(1+\epsilon_{1} \cdot v\right)^{\epsilon_{2}} \times W(\{X\}), \\
& v=\sum_{i=1}^{n n} v_{i}^{d}+\sum_{i=1}^{n m}\left(v_{i}^{\sigma}+v_{i}^{\lambda}\right),
\end{aligned}
$$

where $v$ represents the sum of the violations of the design constraints; $v_{i}^{d}, v_{i}^{\sigma}$ and $v_{i}^{\lambda}$ are respectively constraint violations for displacement, stress and slenderness ratio. The constants $\epsilon_{1}$ and $\epsilon_{2}$ are penalty function exponents that are selected considering the exploration and exploitation rate of the search space. In this case $\epsilon_{1}$ is set to unity; and $\epsilon_{2}$ is chosen in such a way that it diminishes the penalties and is calculated by:

$$
\epsilon_{2}=1.5+1.5 \times \frac{\text { iter }}{\text { iter }_{\max }} \text {. }
$$

As the shape and size optimization is carried out simultaneously, both of the design vectors should have the same size, because the probability of choosing each value of design vectors should be identical by algorithm. Thus, the size of the height design vector (Shape Optimization) is equal to the number of cross-section areas existing in Table 1 (Size Optimization). Therefore, the range of discrete heights from $[0.5,2.3]$ and from $[2,3.8]$ intervals with $0.05 \mathrm{~m}$ increment is considered for small and big span size of double-layer grids to achieve the optimum height, respectively.

\section{Enhanced colliding bodies optimization algorithm}

Colliding bodies optimization (CBO) is a physics-inspired efficient meta-heuristic algorithm which is introduced by Kaveh and Mahdavi [17]. CBO with simple formulation and no necessity for parameter tuning can deal with complex problems without extensive mathematical computations. It is broadly used in various fields of optimization problems. The CBO imitates a 1-dimensional collision between two colliding bodies (CBs) from physics. Inspired by these laws, each $\mathrm{CB}$ collides separately with its pair and updates its new velocity based on momentum and energy conservation law for the 1-dimensional collision. The exploitation phase of $\mathrm{CBO}$ is weak due to the lack of memory to save the best-so-far solution in its 
formulation. In order to improve the performance of $\mathrm{CBO}$, enhanced colliding bodies optimization (ECBO) is introduced using memory to save some of the best solutions and utilizes a mechanism to escape from local optima [18].

\subsection{A concise description and formulation of the main algorithm (CBO)}

In $\mathrm{CBO}$, each agent solution being considered as an object or body with mass known as a Colliding Body (CB). These massed objects consist of two main groups equally; namely stationary and moving objects, these two bodies collide with each other as illustrated in Fig. 1. This collision is done for two purposes: (I) to ameliorate the positions of moving objects and (II) to shift stationary objects to better positions. After the collision, the new positions of colliding bodies are updated based on their new velocities using the collision laws governed by the laws of momentum and energy [17]. The conservation of the total momentum in an isolated system demands that the total momentum before the collision is the same as the total momentum after the collision provided that there are no net external forces acting upon the objects. CBO begins with an initial population of $2 n$ parent individuals generated by a random initialization. Afterward, CBs are classified in ascending order in accordance with the value of the objective function as depicted in Fig. 2.
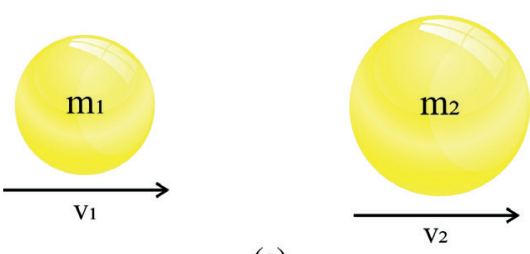

(a)

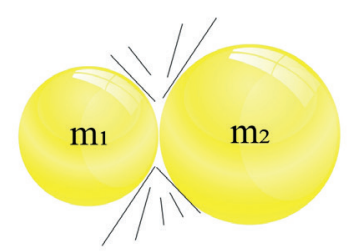

(b)
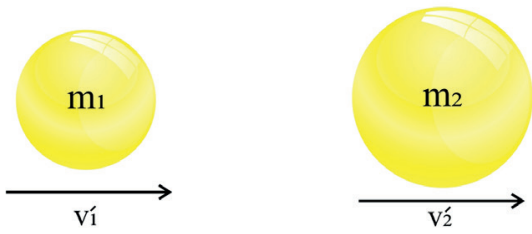

(c)

Fig. 1 The collision between two bodies, (a) before the collision, (b) same time collision and (c) after collision

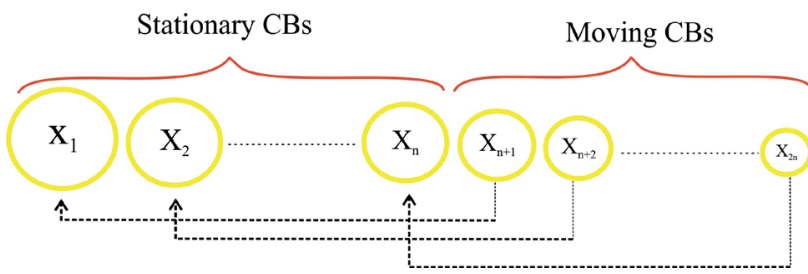

Fig. 2 The classified CBs in an ascending order and the collision mating process

The summary of the $\mathrm{CBO}$ procedure can describe as follows:

The value of the body mass for each $\mathrm{CB}$ is defined as:

$m_{k}=\frac{\frac{1}{f i t(k)}}{\sum_{i=1}^{n} \frac{1}{f i t(i)}}, \quad k=1,2, \ldots, 2 n$,

where $f i t(i)$ illustrates the objective function value of the $i$ th $\mathrm{CB}$ and $2 n$ is the number of population size. CBs are classified in ascending order according to their objective function values. The arranged CBs are equally divided into two groups: (I) stationary group, (II) moving group (Fig. 2). Moving objects move to collide stationary objects in order to improve their positions and push stationary objects towards better positions. Before the collision, the velocity of the stationary objects is zero and for the moving objects this value is equal to the change of the body position as:

$v_{i}=0, \quad i=1, \ldots, n$,

$v_{i}=x_{i-n}-x_{i}, \quad i=n+1, n+2, \ldots, 2 n$,

where $x_{i}$ and $v_{i}$ are the position and velocity vector of the $i$ th CB in this group, respectively; $x_{i-n}$ is the $i$ th CB pair position of $x_{i}$ in previous group. The velocity of each stationary and moving CBs after the collision $\left(v_{i}{ }^{\prime}\right)$ are assessed by:

$v_{i}^{\prime}=\frac{\left(m_{i+n}+\varepsilon m_{i+n}\right) v_{i+n}}{m_{i}+m_{i+n}} \quad i=1,2, \ldots, n$,

$v_{i}^{\prime}=\frac{\left(m_{i}-\varepsilon m_{i-n}\right) v_{i}}{m_{i}+m_{i-n}} \quad i=n+1, n+2, \ldots, 2 n$,

$\varepsilon=1-\frac{\text { iter }}{\text { iter }_{\max }}$,

Where $\varepsilon$ is an index serves as the coefficient of restitution (COR) to control exploration and exploitation rate. iter and iter $_{\text {max }}$ are the actual iteration number and the maximum number of iterations for the optimization process, respectively. 
The new positions of each stationary and moving CBs are evaluated by the following formulas.

$x_{i}^{\text {new }}=x_{i}+\operatorname{rand}_{\circ} v_{i}^{\prime}, \quad i=1,2, \ldots, n$,

$x_{i}^{\text {new }}=x_{i-n}+$ rand $_{\circ} v_{i}^{\prime}, \quad i=n+1, \ldots, 2 n$,

where $x_{i}^{\text {new }}, x_{i}$ and $v_{i}{ }^{\prime}$ are the new position, old position and the velocity after the collision of the $i$ th $\mathrm{CB}$, respectively. rand is a random vector uniformly distributed in the range of $[-1,1]$ and the sign " $\square$ " denotes an element-by-element multiplication.

\subsection{Pseudo-code of the ECBO algorithm}

The enhanced colliding bodies optimization algorithm (ECBO) is introduced in order to get more and faster reliable solutions [19]. This algorithm has a memory that saves a number of best-so-far solutions to improve CBO performance. Additionally, a mechanism is defined to randomly change some components of $\mathrm{CBO}$ to escape from local minima and prevent premature convergence. The following steps are outlined to introduce ECBO algorithm.

\subsubsection{Initialization}

Step 1: The initial location vectors of all CBs are created randomly in search space.

$x_{i}^{0}=x_{\min }+\operatorname{random}_{\mathrm{o}}\left(x_{\max }-x_{\min }\right), i=1,2,3, \ldots, n$,

where $x_{i}^{0}$ is the initial solution vector of the $i$ th CB. $x_{\text {min }}$ and $x_{\max }$ are the minimum and the maximum permissible variables vectors; and random is a random vector with an interval of $[0,1]$ for each component.

\subsubsection{Search}

Step 1: To obtain the value of mass for each CB Eq. (8) is evaluated.

Step 2: In this step, some historically best $\mathrm{CB}$ vectors and their mass and objective function values are saved to Colliding Memory (CM). The population is updated by adding the solution vectors which are saved in CM and the same number of current worst CB are deleted. This mechanism can improve the performance of the algorithm without increasing the computational cost.

Step 3: CBs are classified in ascending order in accordance with the value of the objective function. In order to select the pairs of CBs for collision, they are equally divided into two groups: (I) stationary group, (II) moving group.

Step 4: The velocity of stationary objects before the collision is zero (Eq. (9)). Moreover, moving bodies move toward stationary objects and their velocities before the collision are evaluated by Eq. (10).

Step 5: After the collision, the velocities of stationary and moving bodies are determined by Eqs. (11) and (12), respectively.

Step 6: The new position of each $\mathrm{CB}$ is evaluated by Eqs. (14) or (15).

Step 7: In ECBO a stochastic approach is used to improve the exploration capabilities of the standard CBO and to prevent premature convergence. A parameter such as Pro within $(0,1)$ is introduced to specify whether a component of each CB must be changed or not. For each colliding body, Pro is compared with $r n_{i}(i=1,2, \ldots, n)$ which is a random number uniformly distributed within $(0,1)$. If $r n_{i}<\boldsymbol{P r o}$, one dimension of ith CB is randomly selected and its value is regenerated by

$x_{i j}=x_{j, \min }+$ random $\cdot\left(x_{j, \max }-x_{j, \min }\right)$,

where $x_{i j}$ is the $j$ th variable of the ith CB. $x_{j, \min }$ and $x_{j \text {,max }}$ are the minimum and maximum limits of the $j$ th variable. The value of Pro in this paper set to 0.3 .

\subsubsection{Terminating condition check}

Step 1: After a predefined maximum number of objective function evaluations, the optimization process is terminated. If this is not accomplished go to Step 2 for a new iteration round.

\section{Verification of the proposed method using different optimization algorithms}

In this section, two double-layer grids of small and big sizes with different configurations are optimized to show the capability of the proposed method (Simultaneous shape and size optimization) versus previous method (Shape and size optimization) using different algorithms. The spans of $15 \mathrm{~m} \times 15 \mathrm{~m}$ and $40 \mathrm{~m} \times 40 \mathrm{~m}$ with certain bays of equal length in two directions are considered as small and big size grids. The connections are assumed to be ball-jointed [20], and top layer joints are subjected to concentrated vertical loads corresponding to a uniformly distributed load of $200 \mathrm{~kg} / \mathrm{m}^{2}$. The optimization algorithm is coded in MATLAB and the structures are analyzed using the direct stiffness method. The element grouping and details about their constraints and the algorithm parameters setting are the same as those of [11]. The structures are briefly explained in the following, and the results are presented. 


\subsection{A $15 \mathrm{~m} \times 15 \mathrm{~m}$ Diagonal on diagonal grid}

The diagonal on diagonal grid containing 528 members and 145 nodes is considered as a small size double-layer grid as shown in Fig. 3. Bottom layer is simply supported at the corner nodes. The best results were achieved by the third grouping pattern provided in [11]. Thus, this grouping pattern is selected to optimize the structure using the proposed method. The best weights and their related optimum heights obtained by different algorithms are listed in Table 2. As illustrated, ECBO could find the lightest design compared to other utilized algorithms through the proposed method and its optimum height is equal to $1.55 \mathrm{~m}$. Moreover, comparing the results of ECBO by those of the considered methods shows the ability of this technique in designing double-layer grids. Table 3 lists the optimal designs found by different methods. It is apparent from the table that ECBO does not use any extra strong section while utilizing this technique. As shown in Table 3, the final designs satisfy both stress and displacement constraints. The total computational cost for solving one complete example obtained by ECBO for the previous work was equal to 2 hours and 10 minutes, while this time is equal to 7 minutes for the present work.

\subsection{A $40 \mathrm{~m} \times \mathbf{4 0} \mathrm{m}$ two-way on two-way grid}

Fig. 4 shows the $3 \mathrm{D}$ view of a $40 \mathrm{~m} \times 40 \mathrm{~m}$ two-way on two-way grid. This large span grid has 800 members and 221 nodes. At two parallel sides of the grid, the bottom layer is simply supported as mid-edge. The third grouping

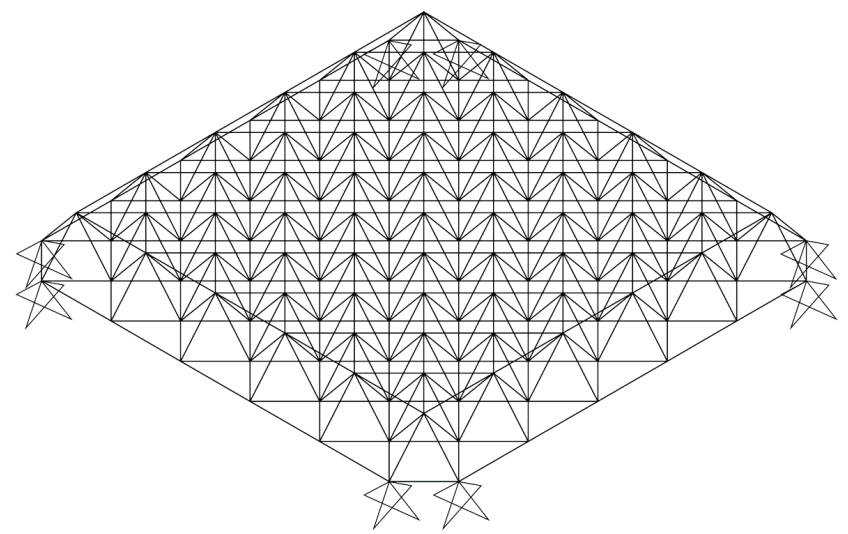

Fig. 3 Schematic of a $15 \mathrm{~m} \times 15 \mathrm{~m}$ diagonal on diagonal grid
Table 3 Optimum design of the $15 \mathrm{~m} \times 15 \mathrm{~m}$ diagonal on diagonal grid

Optimum section (designations)

\begin{tabular}{|c|c|c|c|c|}
\hline \multicolumn{2}{|c|}{ Design Variables } & \multicolumn{2}{|c|}{ Kaveh and Moradveisi [11] } & \multirow{2}{*}{$\begin{array}{c}\text { Present work } \\
\text { ECBO }\end{array}$} \\
\hline & & CBO & ЕСВО & \\
\hline 1 & A1 & ST (1 1/2) & ST $\left(1 \frac{1}{2}\right)$ & ST $\left(1 \frac{1}{2}\right)$ \\
\hline 2 & A2 & ST (2) & ST (2) & ST (2) \\
\hline 3 & A3 & ST (1 1/4) & ST $\left(1 \frac{1}{4}\right)$ & ST $\left(1 \frac{1}{4}\right)$ \\
\hline 4 & A4 & ST (1) & ST (1) & ST (1) \\
\hline 5 & A5 & ST $(1 / 2)$ & ST $(1 / 2)$ & ST $(1 / 2)$ \\
\hline 6 & A6 & ST $(1 / 2)$ & ST $(1 / 2)$ & ST $(1 / 2)$ \\
\hline 7 & A7 & ST $(1 / 2)$ & EST $(1 / 2)$ & ST $(1 / 2)$ \\
\hline 8 & A8 & ST (3) & ST $\left(2 \frac{1}{2}\right)$ & ST $\left(2 \frac{1}{2}\right)$ \\
\hline 9 & A9 & ST (1) & ST $\left(1 \frac{1}{4}\right)$ & ST $\left(1 \frac{1}{4}\right)$ \\
\hline 10 & A 10 & ST (1 1/4) & ST $\left(1 \frac{1}{4}\right)$ & ST $(11 / 4)$ \\
\hline 11 & A11 & $\operatorname{EST}\left(1 \frac{1}{2}\right)$ & ST $\left(1 \frac{1}{2}\right)$ & ST $\left(1 \frac{1}{2}\right)$ \\
\hline 12 & A12 & $\operatorname{EST}\left(1 \frac{1}{2}\right)$ & $\operatorname{EST}\left(1 \frac{1}{2}\right)$ & ST $\left(1 \frac{1}{2}\right)$ \\
\hline 13 & A13 & $\operatorname{EST}\left(1 \frac{1}{2}\right)$ & $\operatorname{EST}\left(1 \frac{1}{2}\right)$ & ST $\left(1 \frac{1}{2}\right)$ \\
\hline 14 & A14 & ST (2) & ST (2) & ST (2) \\
\hline 15 & A15 & ST (1) & ST (1) & ST (1) \\
\hline 16 & A16 & ST (1) & ST (1) & ST (1) \\
\hline 17 & A17 & ST (1) & ST (1) & ST (1) \\
\hline 18 & A18 & ST (1) & ST (1) & ST (1) \\
\hline 19 & A19 & ST (1) & ST (1) & ST (1) \\
\hline 20 & Optimum height (m) & 1.5 & 1.5 & 1.55 \\
\hline $\mathrm{Ma}$ & Stress Ratio & 0.9980 & 0.9956 & 0.9832 \\
\hline $\mathrm{Ma}$ & Displacement Ratio & 0.9246 & 0.9955 & 0.9907 \\
\hline $\mathrm{Be}$ & weight (kg) & 3917.5032 & 3794.8357 & 3786.6645 \\
\hline
\end{tabular}

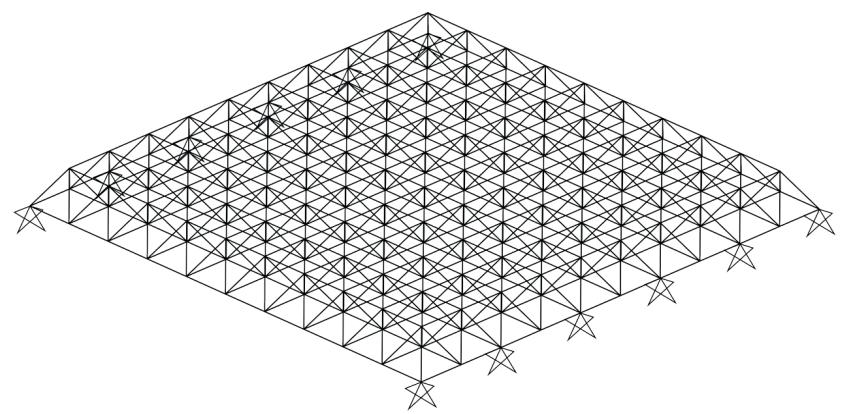

Fig. 4 Schematic of a $40 \mathrm{~m} \times 40 \mathrm{~m}$ Two-way on two-way grid

pattern leads to 24 design variables for this type of grid and by considering height of the structure as a design variable, the total number of design variables is equal to 25 . Table 4 demonstrates the efficiency of algorithms,

Table 2 Performance comparison of the $15 \mathrm{~m} \times 15 \mathrm{~m}$ diagonal on diagonal grid for the third grouping pattern

\begin{tabular}{lccccc}
\hline & \multicolumn{3}{c}{ Kaveh et al [10] } & \multicolumn{2}{c}{ Kaveh and Moradveisi [11] } \\
\hline Algorithms & CS & HBB-BC & HPSACO & CBO & ECBO \\
Best weight $(\mathrm{kg})$ & 4180.124 & 5643.173 & 5270.756 & 3917.503 & 3794.836 \\
Optimum height $(\mathrm{m})$ & 1.5 & 1 & 1.5 & 1.5 & 1.5 \\
\hline
\end{tabular}


Table 4 Performance comparison of the $40 \mathrm{~m} \times 40 \mathrm{~m}$ two-way on two-way grid for the third grouping pattern

\begin{tabular}{lccccc}
\hline & & Kaveh et al [10] & & \multicolumn{2}{c}{ Kaveh and Moradveisi [11] } \\
\hline Algorithms & CS & HBB-BC & HPSACO & CBO & ECBO \\
Best weight $(\mathrm{kg})$ & 58474.360 & 79576.315 & 79390.971 & 67247.606 & 58142.691 \\
Optimum height $(\mathrm{m})$ & 3 & 3 & 3 & 3 & 36799.4996 \\
\hline
\end{tabular}

where the best-obtained weight is hatched for each case. Concerning the result of low weight designs, ECBO weight is $1343.19 \mathrm{~kg}(2.3 \%)$ lighter than the best design of the previous works utilizing the proposed method while its optimum height is equal to $3.35 \mathrm{~m}$. Table 5 indicates the best design vectors and the corresponding weights for different methods. This table shows the better performance of the present technique in terms of low weight design. As can be seen, none of the optimum designs violate the constraints. The overall computational cost for solving one complete example obtained by ECBO for the previous work was 3 hours and 42 minutes, whereas this time for the present work is equal to 11 minutes.

\section{Nonlinear behavior of the grids}

Studies show that some trusses show nonlinear behavior even in the usual loading range [21, 22]. Therefore, neglecting nonlinear effects in structural design optimization can lead to the uneconomic design and for this reason in the case of nonlinear optimization, geometrical and material nonlinearity effects are taken into account. Thus, a 3-D uniaxial Co-rotational truss element is utilized to model structural elements. This finite element has plasticity and large deflection capabilities. In order to select the material a uniaxial bilinear steel material with kinematic hardening exist in OpenSees [23] platform is considered as shown in Fig. 5. The strain-hardening ratio that is the ratio between the post-yield tangent and elastic tangent is equal to 0.01 . In the nonlinear structural analysis process, instead of the linear strain, a nonlinear one is used. Since the strains are nonlinear functions of the displacements or when the stresses reach values exceeding the yield stress of the material, the stress to strain relationship is nonlinear. In these cases, the stiffness is dependent on the displacements and the strains. Obviously, the solution of the displacements can not be obtained in a single step. Instead, the analysis is carried out by the incremental method combined with some iterative equilibrium corrections at every step [24, 25]. In the process of optimization, structure requires multiple nonlinear analyses to achieve the optimal design. Algorithm is coded in MATLAB and it generates the design variables. The data should be transferred to Opensees for analyses
Table 5 Optimum design of the $40 \mathrm{~m} \times 40 \mathrm{~m}$ two-way on two-way grid

Optimum section (designations)

\begin{tabular}{|c|c|c|c|c|}
\hline & \\
\hline & \multirow[t]{2}{*}{ Design Variables } & \multicolumn{2}{|c|}{ Kaveh and Moradveisi [11] } & \multirow{2}{*}{$\begin{array}{c}\text { Present work } \\
\text { ECBO }\end{array}$} \\
\hline & & $\mathrm{CBO}$ & ECBO & \\
\hline 1 & $\mathrm{~A} 1$ & ST (5) & ST (4) & ST (4) \\
\hline 2 & $\mathrm{~A} 2$ & ST (6) & EST (5) & ST (5) \\
\hline 3 & A3 & ST (3 1/2) & DEST (2) & ST (1 1/4) \\
\hline 4 & A4 & ST (5) & ST (4) & ST (3) \\
\hline 5 & A5 & ST (3 1/2) & ST (3) & EST (3) \\
\hline 6 & A6 & ST $(21 / 2)$ & ST $\left(1 \frac{1 / 4}{4}\right)$ & EST $\left(1 \frac{1}{2}\right)$ \\
\hline 7 & A7 & EST (1 1 1/2) & EST (2) & DEST (2) \\
\hline 8 & A8 & ST $(21 / 2)$ & $\operatorname{EST}(11 / 2)$ & ST (3) \\
\hline 9 & A9 & $\operatorname{EST}\left(1 \frac{1}{2}\right)$ & ST (3) & ST (3) \\
\hline 10 & A 10 & $\mathrm{ST}\left(2 \frac{1}{2}\right)$ & $\operatorname{EST}(31 / 2)$ & $\operatorname{DEST}(2 \quad 1 / 2)$ \\
\hline 11 & A11 & ST (6) & ST (8) & ST (6) \\
\hline 12 & $\mathrm{~A} 12$ & ST (5) & ST (4) & ST (4) \\
\hline 13 & A 13 & ST (6) & ST (5) & ST (6) \\
\hline 14 & A14 & ST (6) & ST (5) & ST (5) \\
\hline 15 & A15 & ST (6) & EST (5) & ST (6) \\
\hline 16 & A16 & ST (6) & EST (5) & ST (5) \\
\hline 17 & A17 & ST (8) & DEST (4) & ST (5) \\
\hline 18 & A18 & ST (6) & ST (8) & ST (6) \\
\hline 19 & A19 & DEST (8) & ST (8) & ST (6) \\
\hline 20 & A20 & ST (5) & ST (4) & ST (5) \\
\hline 21 & A21 & ST (5) & ST (4) & ST (4) \\
\hline 22 & A22 & $\operatorname{ST}(31 / 2)$ & $\operatorname{ST}\left(3 \frac{1}{2}\right)$ & ST (3) \\
\hline 23 & A23 & $\mathrm{ST}(31 / 2)$ & $\mathrm{ST}\left(2 \frac{1}{2}\right)$ & $\mathrm{ST}(21 / 2)$ \\
\hline 24 & A24 & $\mathrm{ST}(31 / 2)$ & $\operatorname{ST}\left(2 \frac{1}{2}\right)$ & ST $(21 / 2)$ \\
\hline 25 & Optimum height (m) & 3 & 3 & 3.35 \\
\hline $\operatorname{Max}$ & x Stress Ratio & 0.9443 & 0.9973 & 0.9999 \\
\hline $\operatorname{Max}$ & x Displacement Ratio & 0.9736 & 0.9993 & 0.9316 \\
\hline Best & t weight (kg) & 67247.606 & 58142.6912 & 56799.4996 \\
\hline
\end{tabular}

and the results should be returned to MATLAB. Thus, the challenge is to connect OpenSees with MATLAB. This is done through the interface code provided in MATLAB, automatically allowing them to work together in a loop.

\section{Structural models}

In this section, two widely used configurations of doublelayer grids namely two-way on two-way and diagonal on diagonal grids are considered [1]. Two spans of $12 \mathrm{~m} \times 12 \mathrm{~m}$ and $30 \mathrm{~m} \times 30 \mathrm{~m}$ with certain bays of equal length in two 


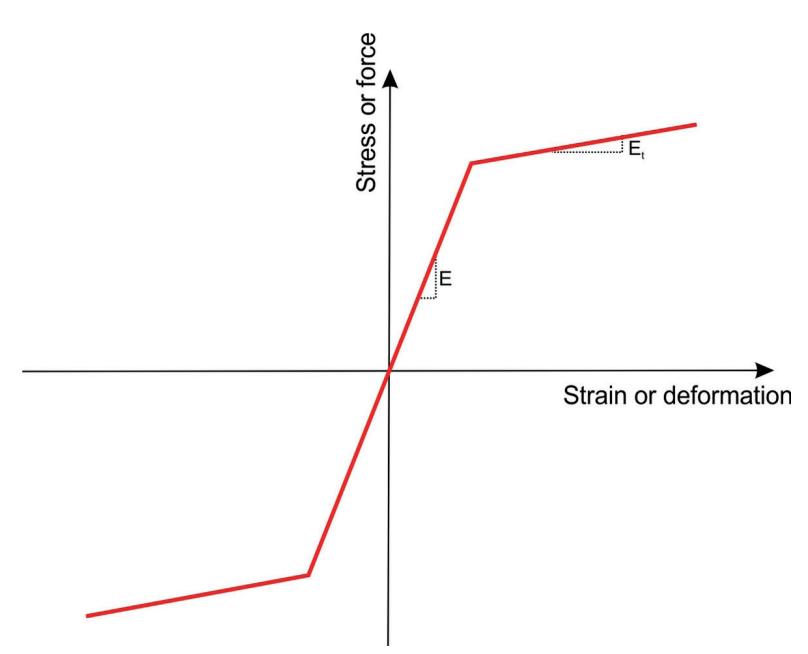

Fig. 5 The stress-strain relationship of a uniaxial bilinear steel material

directions are respectively considered as small and big size grids. The bottom layer at the corner nodes is simply supported. One of the important issues for large-scale structures is the monotony of the distribution of stiffness in the vicinity of the structure. When a part of the structure contains elements with low cross-sections due to low axial forces and small displacements and instead, another portion includes elements with high cross-sections, then the monotony of distribution of the stiffness will not be attained. Therefore, in order to achieve a uniform distribution of stiffness in the entire structure, members are divided into several groups according to two symmetry lines of configuration. Thus, a square-like fashion around the central node is considered to arrange all elements at the top and bottom layer and also diagonal members into different groups. Only a quarter of the grids appear in figures due to symmetry.

\section{Numerical examples}

All double-layer grid connections are considered to be ball-jointed with no moment or torsional resistance and the concentrated vertical loads transmitted from the uniformly distributed load of $200 \mathrm{~kg} / \mathrm{m}^{2}$ are applied to the top layer joints according to their load-bearing areas. Strength and slenderness limitations (Eqs. (3-5)) based on AISC-LRFD provisions as stated earlier and all nodes in the vertical direction were subject to displacement limitations of span/360. The modulus of elasticity, the yield stress and the tangent modulus of elasticity are considered as $200 \mathrm{kN} / \mathrm{mm}^{2}$ (29000 ksi), 248.2 MPa (36 ksi) and $2 \mathrm{kN} / \mathrm{mm}^{2}$ (290 ksi), respectively. For the ECBO algorithm, a population size $(n)$ of 30 individuals is utilized and the size of colliding memory (CM) is considered $n / 10$ that is taken as 3. The maximum number of optimization iterations is set as 9000 analyses for all examples. In all issues, CBs are permitted to choose discrete values of the height design vector, and also select from the allowable list of cross-sections, simultaneously (real numbers are rounded to the nearest integer in each iteration).

\subsection{A $12 \mathrm{~m} \times 12 \mathrm{~m}$ double-layer square grid}

A double-layer grid of $12 \mathrm{~m} \times 12 \mathrm{~m}$ span is classified as a small-size grid. The first common type is two-way on two-way grid containing 392 members and 113 nodes as shown in Fig. 6. The second one is diagonal on diagonal grid with 528 members and 145 nodes as illustrated in Fig. 7. Fig. 8 demonstrate the element grouping with 15 and 17 design variables for two-way on two-way and diagonal on diagonal grids, respectively. Consequently, there are two shape-size optimization problems with 16 and 18 variables (height of the structure is also considered as a design variable). The results find by ECBO are summarized in Table 6. ECBO achieves the lightest design for

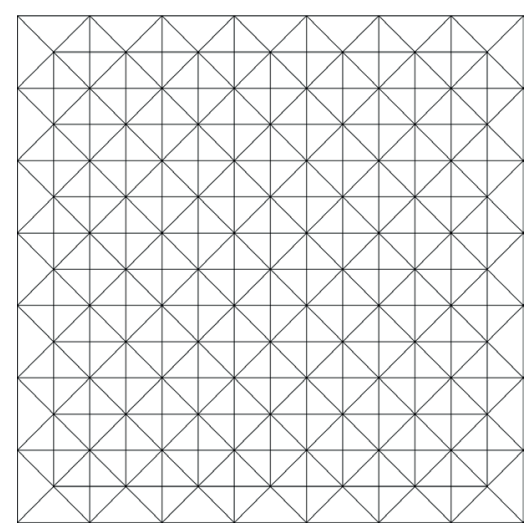

(a) Plan view

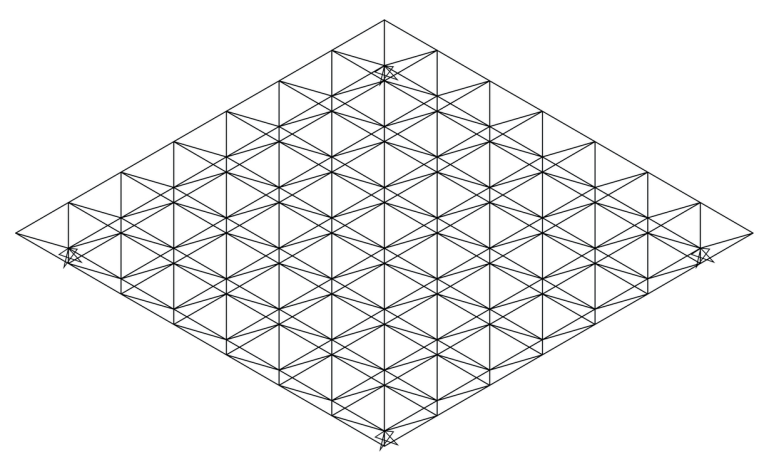

(b) $3 \mathrm{D}$ view

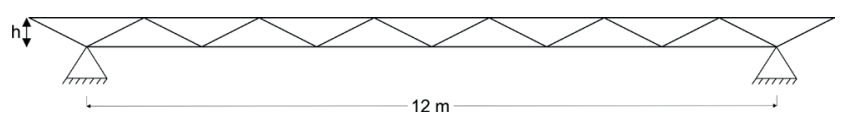

(c) Side view

Fig. 6 Schematic of a $12 \mathrm{~m} \times 12 \mathrm{~m}$ two-way on two-way grid 


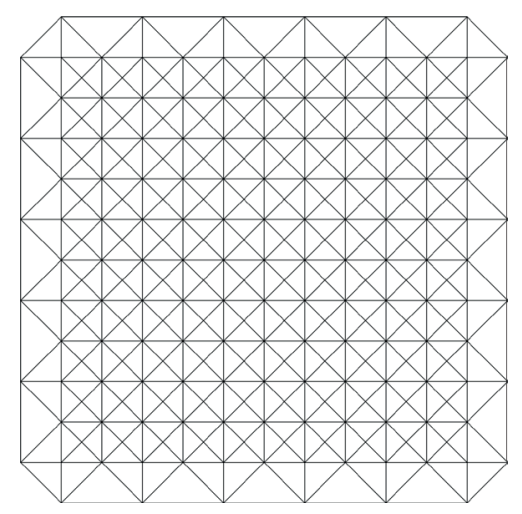

(a) Plan view

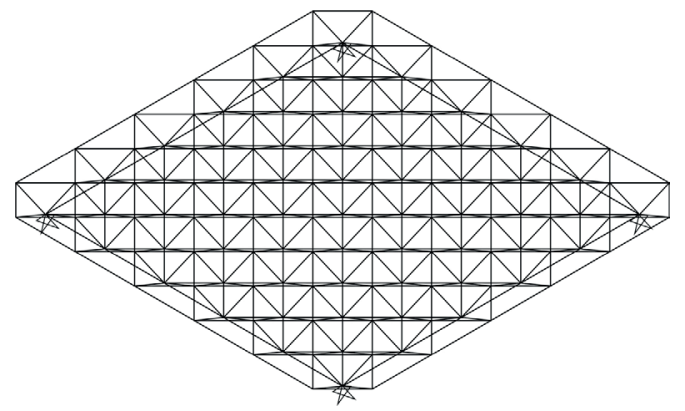

(b) 3D view

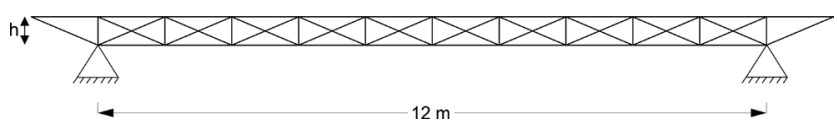

(c) Side view

Fig. 7 Schematic of a $12 \mathrm{~m} \times 12 \mathrm{~m}$ diagonal on diagonal grid

two-way on two-way grid that is $361.47 \mathrm{~kg}$ (11\%) lighter than diagonal on diagonal grid and it can be mentioned that two-way on two-way grid is a cost-effective choice for covering small span cases. The numerical results indicate that the best height for both types is equal to 1 $\mathrm{m}$. Stress ratio and displacement ratio evaluated at the best design optimized by ECBO are shown in Fig. 9 and
Table 6 Optimal design of the $12 \mathrm{~m} \times 12 \mathrm{~m}$ double-layer grids via ECBO algorithm

\begin{tabular}{|c|c|c|c|}
\hline \multirow{2}{*}{\multicolumn{2}{|c|}{ Design Variables }} & \multicolumn{2}{|c|}{ Optimum section (designations) } \\
\hline & & \multirow{2}{*}{$\begin{array}{c}\text { Two-way on two- } \\
\text { way grid }\end{array}$} & \multirow{2}{*}{$\frac{\begin{array}{c}\text { Diagonal on } \\
\text { diagonal grid }\end{array}}{\text { ST (2) }}$} \\
\hline 1 & A1 & & \\
\hline 2 & A2 & ST $(3 / 4)$ & ST (1) \\
\hline 3 & A3 & ST (2) & EST $\left(1 \frac{1}{2}\right)$ \\
\hline 4 & A4 & ST $\left(1 \frac{1}{4}\right)$ & ST (2) \\
\hline 5 & A5 & ST $\left(1 \frac{1}{2}\right)$ & ST (2) \\
\hline 6 & A6 & ST (2) & EST $\left(1 \frac{1}{2}\right)$ \\
\hline 7 & A7 & ST $(1 \quad 1 / 4)$ & ST (1) \\
\hline 8 & A8 & ST (1) & ST $(3 / 4)$ \\
\hline 9 & A9 & ST $(11 / 2)$ & ST (3/4) \\
\hline 10 & A10 & ST (2) & ST $(3 / 4)$ \\
\hline 11 & A11 & ST $(3 / 4)$ & ST $(3 / 4)$ \\
\hline 12 & A12 & ST (1) & ST (2) \\
\hline 13 & A13 & ST $(3 / 4)$ & ST $(11 / 2)$ \\
\hline 14 & A14 & ST $(3 / 4)$ & ST (1) \\
\hline 15 & A15 & ST $(3 / 4)$ & ST $(1 / 2)$ \\
\hline 16 & A16 & N/A & EST $(3 / 4)$ \\
\hline 17 & A17 & N/A & ST $(1 / 2)$ \\
\hline 18 & Optimum Height (m) & 1 & 1 \\
\hline \multicolumn{2}{|c|}{ Max Stress Ratio } & 0.9990 & 0.9997 \\
\hline \multicolumn{2}{|c|}{ Max Displacement Ratio } & 0.8787 & 0.9520 \\
\hline \multicolumn{2}{|c|}{ Best Weight $(\mathrm{kg})$} & 2925.76 & 3287.24 \\
\hline
\end{tabular}

Fig. 10, respectively. The maximum stress ratios for the best design of ECBO are $99.90 \%$ and $99.97 \%$ while the maximum displacement ratios are $87.87 \%$ and $95.20 \%$ for two-way on two-way and diagonal on diagonal grids, respectively. Convergence histories are depicted in Fig. 11. It is apparent from this figure that if the height of the structure is considered as a design variable the diagonal on diagonal grid with a larger number of members can

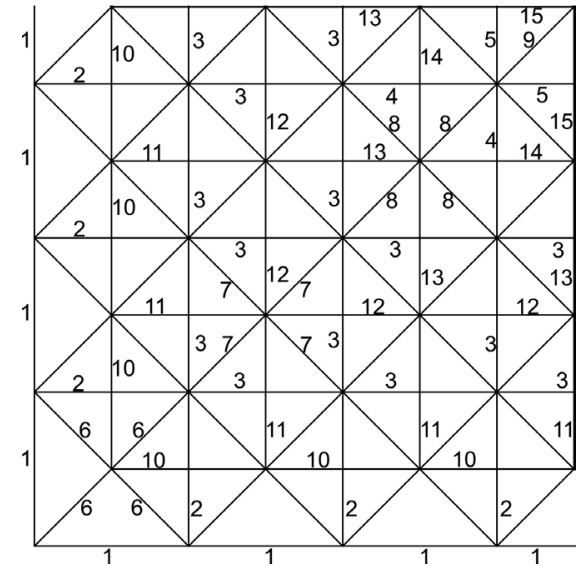

(a)

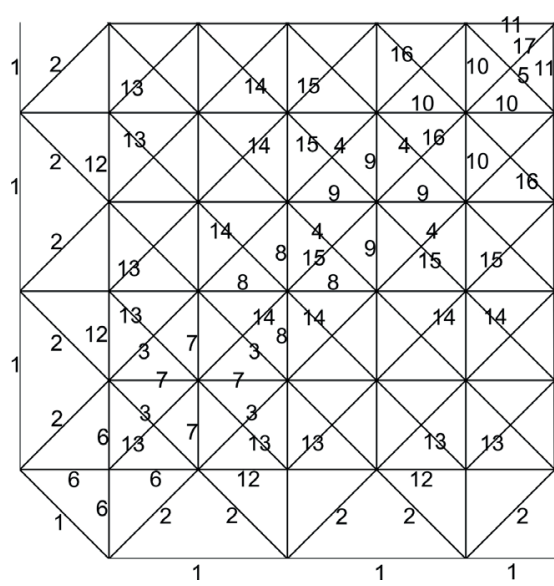

(b)

Fig. 8 Element grouping of the $12 \mathrm{~m} \times 12 \mathrm{~m}$ (a) Two-way on two-way grid, (b) Diagonal on diagonal grid 


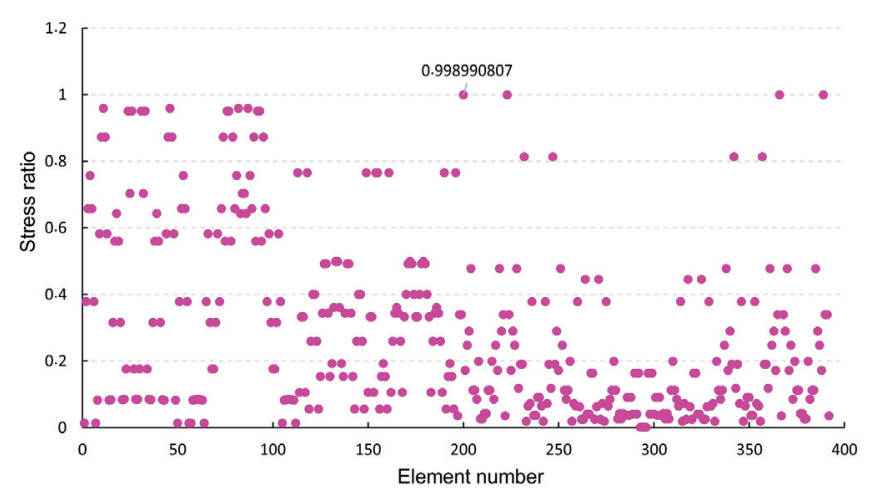

(a)

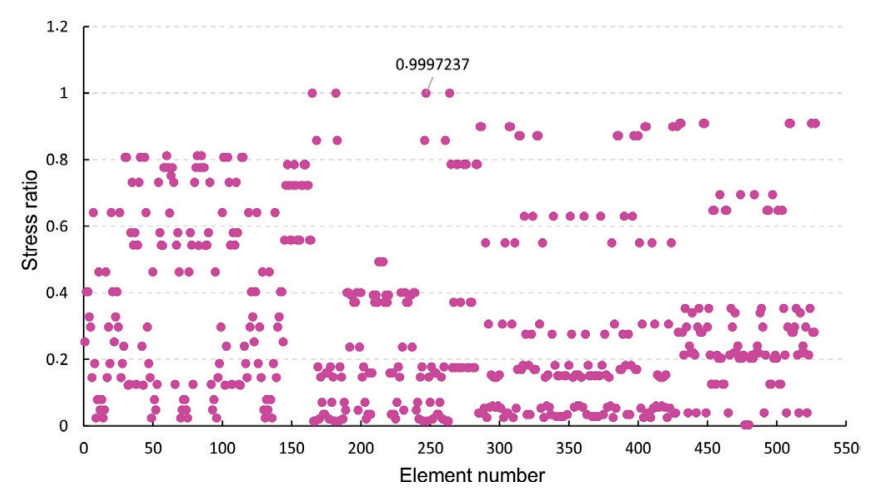

(b)

Fig. 9 The stress ratios for the best design of $12 \mathrm{~m} \times 12 \mathrm{~m}$ double-layer square grids (a) Two-way on two-way grid (b) Diagonal on diagonal grid

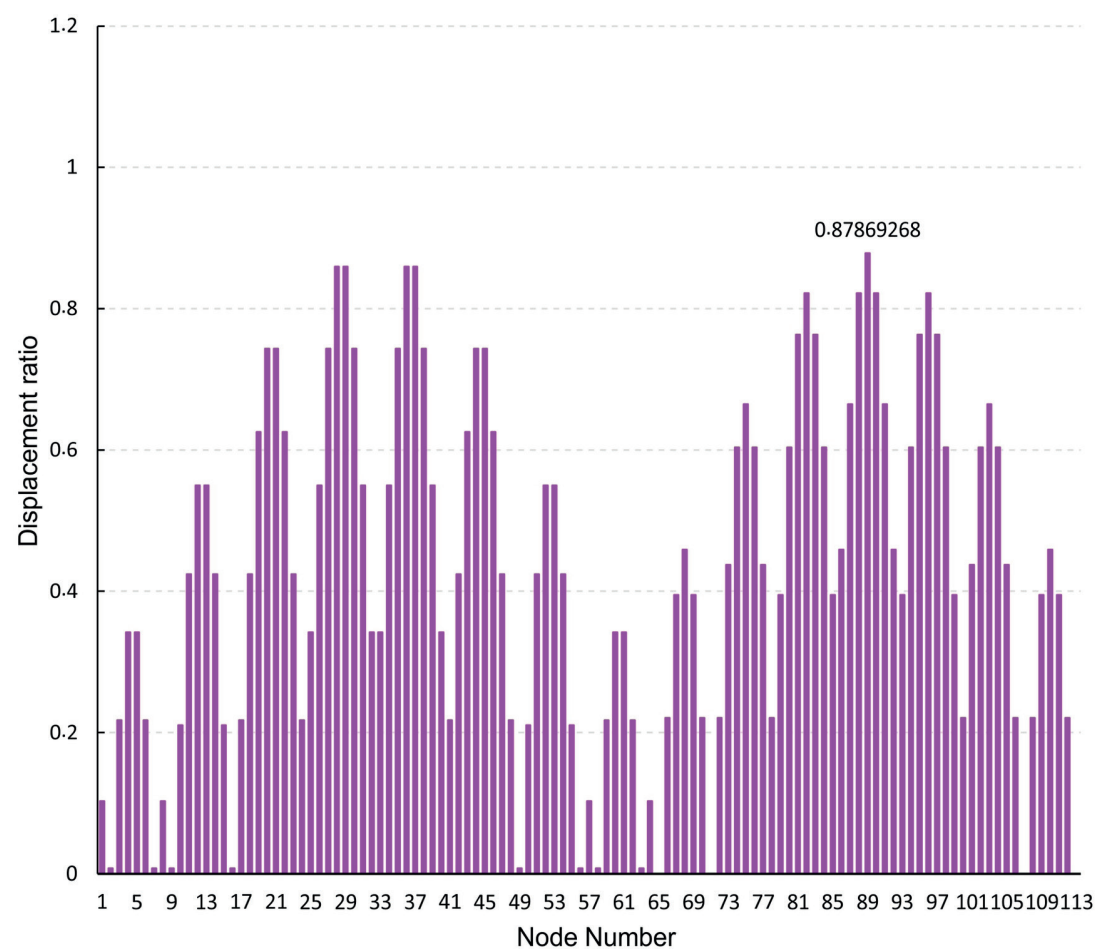

(a)

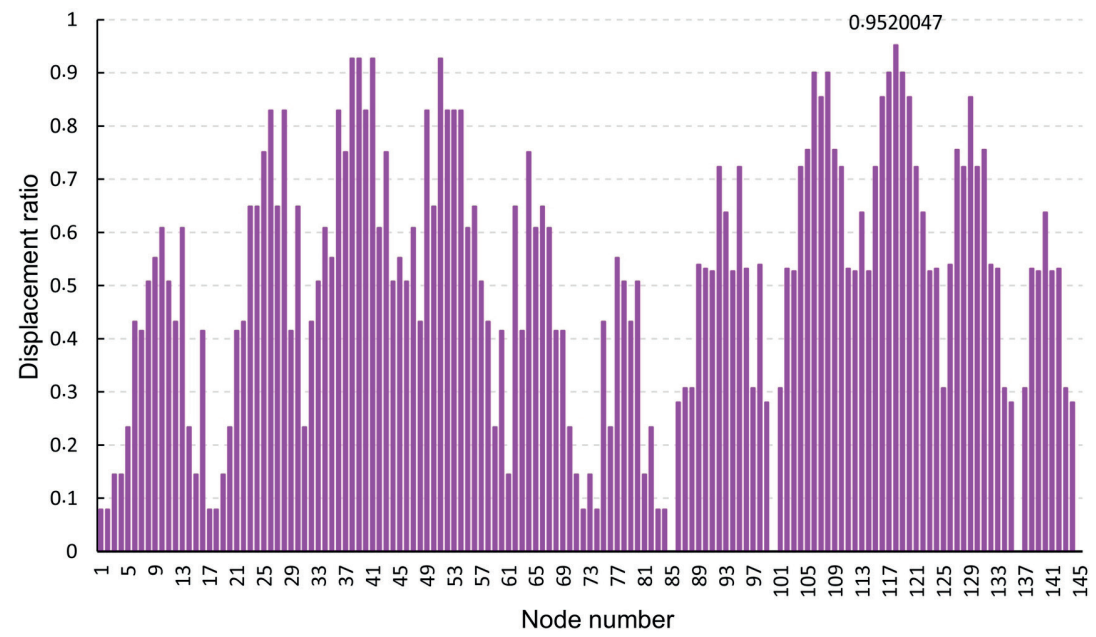

(b)

Fig. 10 The displacement ratios for the best design of $12 \mathrm{~m} \times 12 \mathrm{~m}$ double-layer square grids (a) Two-way on two-way grid (b) Diagonal on diagonal grid 


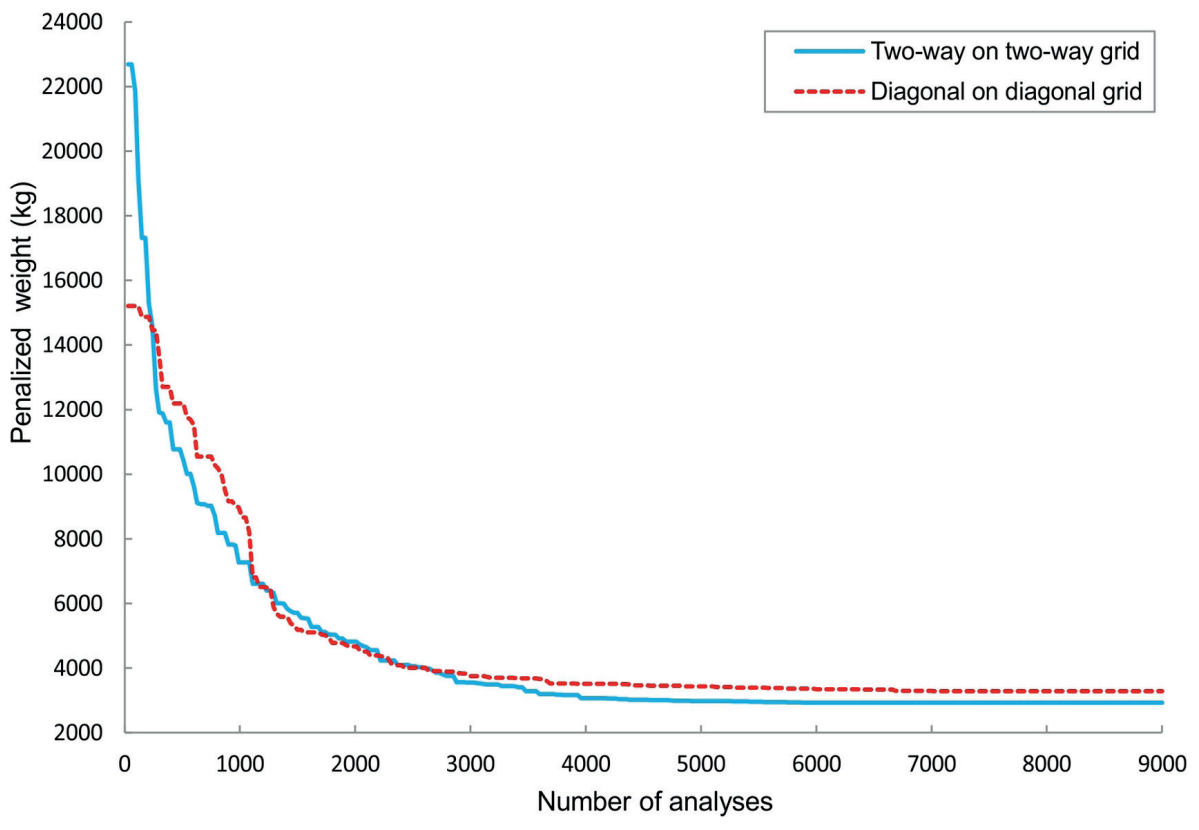

Fig. 11 Convergence curves for the $12 \mathrm{~m} \times 12 \mathrm{~m}$ double-layer grids

also be a proper form for small span cases double-layer grids. Generally, the crucial difference between rectangular and diagonal grids is that the former the beams are of changing length $(L)$ and for this reason, if all the beams have equal cross-sectional areas and the same axial stiffness $(E A)$, their relative stiffness $(E A / L)$ changes significantly. The diagonal grid is composed of beams that form an oblique angle with the walls. Hence, this form is often used in small span cases because its greater rigidity contributes to a substantial decline in deflections, and without regard to the number and intricacy of the joints is often preferred by architects and engineers due to convenience and attractive features.

\section{$7.2 \mathrm{~A} 12 \mathrm{~m} \times 12 \mathrm{~m}$ square on larger square grid}

The second example provides a comparison between two types of the $12 \mathrm{~m} \times 12 \mathrm{~m}$ square on larger square double-layer grids. The square on larger square grid is the type of grid that has some internal openings in the middle of the structure created by omitting some inner square pyramids alternatively to form larger grids in the bottom layer. This change will reduce the total number of members and consequently the weight. It is also visually appealing as the extra openness of the space grids network provides a magnificent architectural effect. Skylights can be installed within the openings. This kind of system is usually suitable for the structures under the normal range of loads. For better comparison, the framing patterns are similar to that of usual types discussed in the previous section.

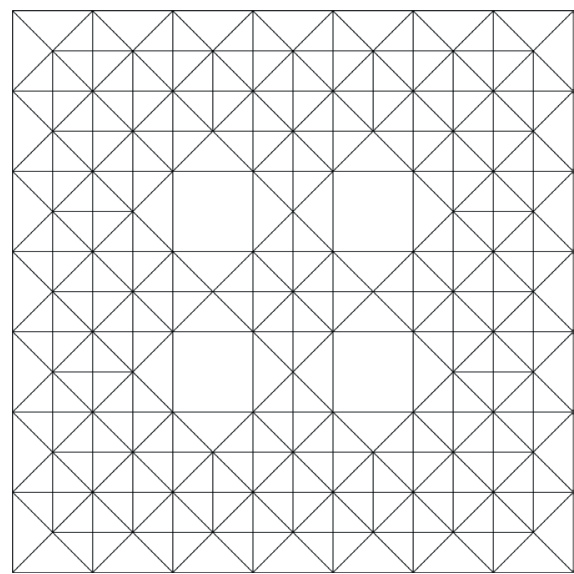

(a)

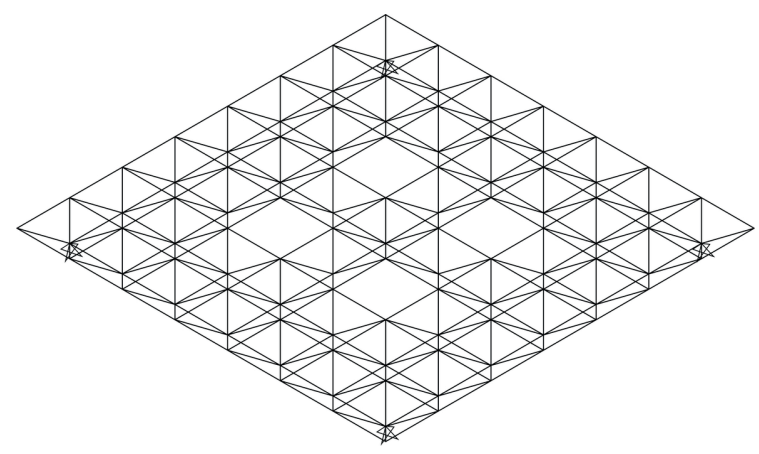

(b)

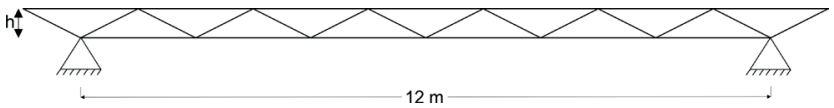

(c)

Fig. 12 Schematic of a $12 \mathrm{~m} \times 12 \mathrm{~m}$ two-way on larger two-way grid 
Fig. 12 shows the schematic of the two-way on larger twoway grid. This structure has 360 members and 109 nodes as the first type. The second type is diagonal on larger diagonal grid has 432 members and 133 nodes shown in Fig. 13. For the purpose of practical design, the uniformly distributed load of $200 \mathrm{~kg} / \mathrm{m}^{2}$ is transmitted to the concentrated vertical loads in the proportion of their load-bearing area assigned to the nodes of the top grid.

For clarity and in order to better understand which bottom layer elements are eliminated, Fig. 14 illustrates the only bottom layer element grouping and both the top and diagonal layer element grouping are following the pattern shown in Fig. 8. The cross-sectional areas of the members of two-way on larger two-way grid are divided into 14 groups and all 432 members of diagonal on larger diagonal grid are categorized into 18 groups. By considering height of the structure as a design variable the total

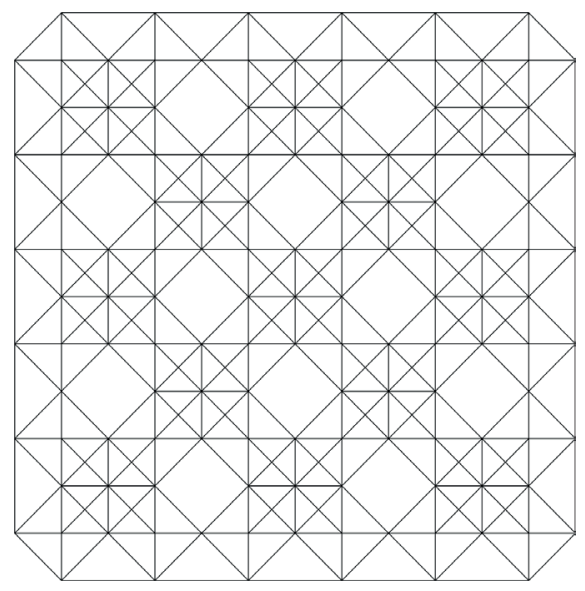

(a)

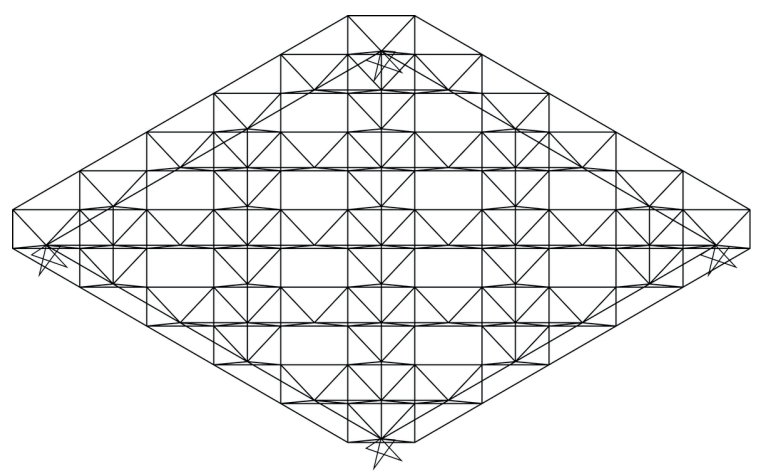

(b)

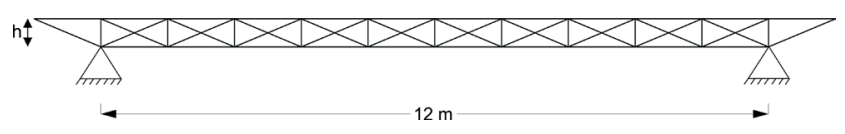

(c)

Fig. 13 Schematic of a $12 \mathrm{~m} \times 12 \mathrm{~m}$ diagonal on larger diagonal grid

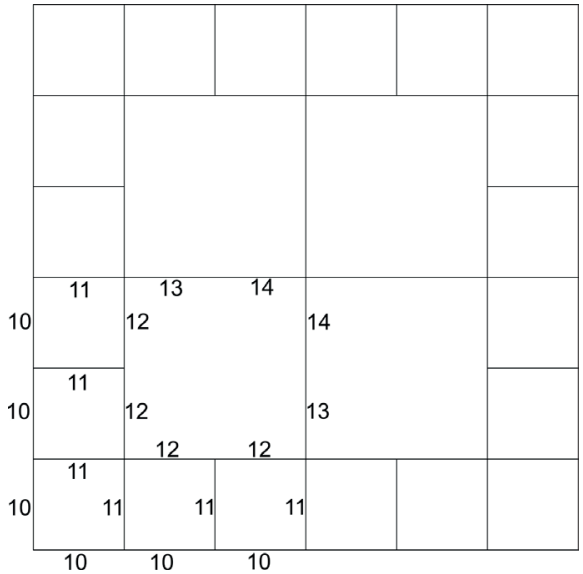

(a)

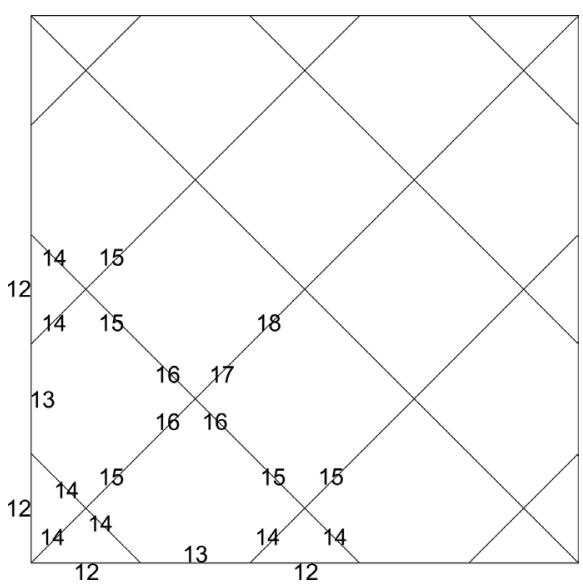

(b)

Fig. 14 Element grouping of the $12 \mathrm{~m} \times 12 \mathrm{~m}$ bottom layer (a) Two-way on larger two-way grid, (b) Diagonal on larger diagonal grid

number of design variables is equal to 15 and 19 variables for two-way on larger two-way grid and diagonal on larger diagonal grid, respectively. Table 7 compare the optimization results for both types. The optimum weights found by the algorithm are equal to $2860.07 \mathrm{~kg}$ and $3005.50 \mathrm{~kg}$ for two-way on larger two-way grid and diagonal on larger diagonal grid, respectively. Results show that two-way on larger two-way grid is $145.43 \mathrm{~kg}(4.84 \%)$ lighter than diagonal on larger diagonal grid. The optimum height obtained by ECBO is equal to $1.15 \mathrm{~m}$ and $1.05 \mathrm{~m}$ for two-way on larger two-way grid and diagonal on larger diagonal grid, respectively. Fig. 15 provides the convergence diagrams of the ECBO in 9000 analyses. Investigation of the convergence curves in Fig. 15 provide the fact that if the height of the structure is flexible to choose the diagonal on larger diagonal grid is also suitable form for covering small span length even with larger number of members. Figs. 16 and 17 demonstrate the existing stress and displacement ratios for the best design of ECBO algorithm. 
Table 7 Optimal design of the $12 \mathrm{~m} \times 12 \mathrm{~m}$ square on larger square double-layer grids via ECBO algorithm

\begin{tabular}{|c|c|c|c|}
\hline & \multirow[b]{2}{*}{ Design Variables } & \multicolumn{2}{|c|}{ Optimum section (designations) } \\
\hline & & $\begin{array}{l}\text { Two-way on } \\
\text { two-way grid }\end{array}$ & $\begin{array}{l}\text { Diagonal on } \\
\text { diagonal grid }\end{array}$ \\
\hline 1 & A1 & EST $\left(1 \frac{1}{2}\right)$ & ST (2) \\
\hline 2 & A2 & ST $(3 / 4)$ & ST (1) \\
\hline 3 & A3 & ST (2) & $\operatorname{EST}\left(1 \frac{1}{2}\right)$ \\
\hline 4 & A4 & ST $\left(\begin{array}{ll}1 & 1 / 4\end{array}\right)$ & ST (2) \\
\hline 5 & A5 & ST $\left(\begin{array}{ll}1 & 1 / 4\end{array}\right)$ & ST (2) \\
\hline 6 & A6 & ST (2) & $\operatorname{EST}\left(1 \frac{1}{2}\right)$ \\
\hline 7 & A7 & ST $\left(\begin{array}{ll}1 & 1 / 4\end{array}\right)$ & ST (1) \\
\hline 8 & A8 & ST (1) & ST (1) \\
\hline 9 & A9 & ST (1) & $\operatorname{EST}(3 / 4)$ \\
\hline 10 & $\mathrm{~A} 10$ & $\operatorname{EST}\left(1 \frac{1}{2}\right)$ & $\mathrm{ST}(3 / 4)$ \\
\hline 11 & A11 & ST $(3 / 4)$ & ST $(3 / 4)$ \\
\hline 12 & A12 & $\mathrm{ST}(3 / 4)$ & ST (2) \\
\hline 13 & A13 & ST $\left(\begin{array}{ll}1 & 1 / 2\end{array}\right)$ & ST $(3 / 4)$ \\
\hline 14 & A14 & EST (1) & $\operatorname{EST}\left(1 \frac{1}{2}\right)$ \\
\hline 15 & A15 & N/A & ST $\left(\begin{array}{ll}1 & 1 / 4\end{array}\right)$ \\
\hline 16 & A16 & $\mathrm{N} / \mathrm{A}$ & ST (1) \\
\hline 17 & A17 & N/A & $\operatorname{EST}(1 / 2)$ \\
\hline 18 & A18 & N/A & ST $(1 / 2)$ \\
\hline 19 & Optimum Height (m) & 1.15 & 1.05 \\
\hline $\mathrm{Ma}$ & Stress Ratio & 0.9989 & 0.9984 \\
\hline Ma & Displacement Ratio & 0.7755 & 0.9886 \\
\hline Bes & Weight (kg) & 2860.07 & 3005.50 \\
\hline
\end{tabular}

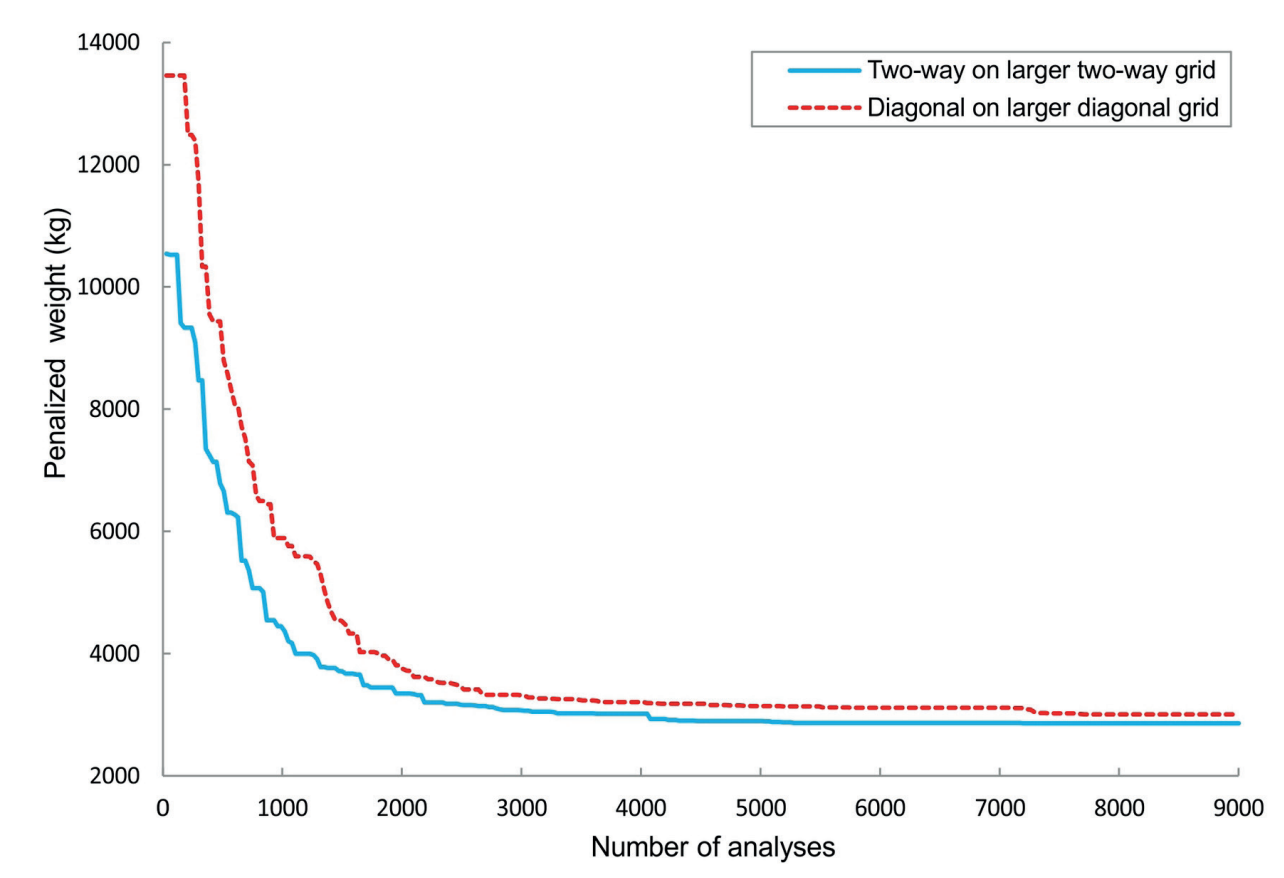

Fig. 15 Convergence curves for the $12 \mathrm{~m} \times 12 \mathrm{~m}$ square on larger square double-layer grids

\subsection{A $30 \mathrm{~m} \times 30 \mathrm{~m}$ double-layer square grid}

Optimal design of a $30 \mathrm{~m} \times 30 \mathrm{~m}$ large-scale pin-jointed double-layer grids is considered as the last example. Fig. 18 shows the geometric details of the two-way on two-way grid as the first common type has 968 members and 265 nodes. Latter type is diagonal on diagonal grid with 1520 members and 401 nodes illustrated in Fig. 19. According to the symmetry, the element grouping of a quarter of the grids is shown in Fig. 20. The cross-sectional areas of members are divided into 23 and 27 design variable groups for two-way on two-way and diagonal on diagonal grid, respectively. By considering the range of discrete heights from $[2,3.8]$ interval with $0.05 \mathrm{~m}$ increment there are two shape-size optimization problems with 24 and 28 variables. Table 8 demonstrates the best designs and their corresponding weights for two types of double-layer grids. The optimum design obtained by the ECBO algorithm is weighted $41904.34 \mathrm{~kg}$ for twoway on two-way grid which is 8.5 percent lighter than the weight is hatched for diagonal on diagonal grid is taken as $45796.86 \mathrm{~kg}$. It can be inferred that two-way on twoway grid is a more affordable form for covering big span cases. The optimum height achieved by ECBO is equal to $2.65 \mathrm{~m}$ and $2.4 \mathrm{~m}$ for two-way on two-way grid and diagonal on diagonal grid, respectively. The convergence rates of the best result found by the proposed method are provided in Fig. 21. Figs. 22 and 23 show the stress ratio and displacement ratio evaluated at the best design optimized 


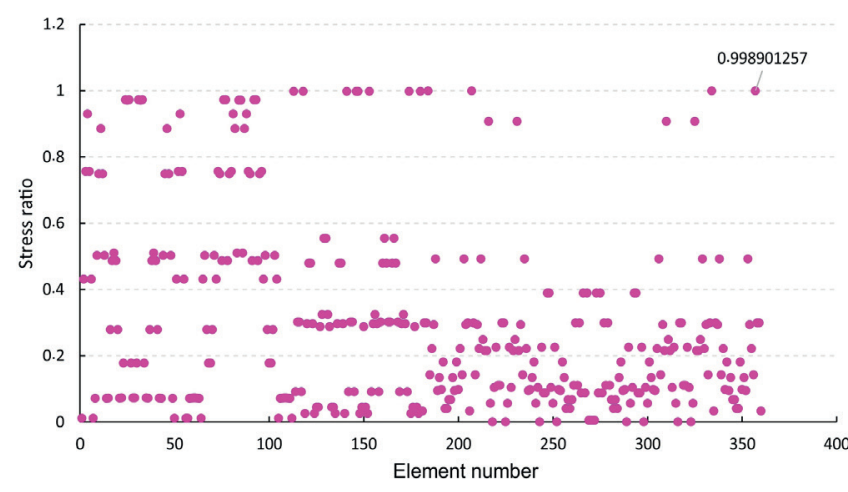

(a)

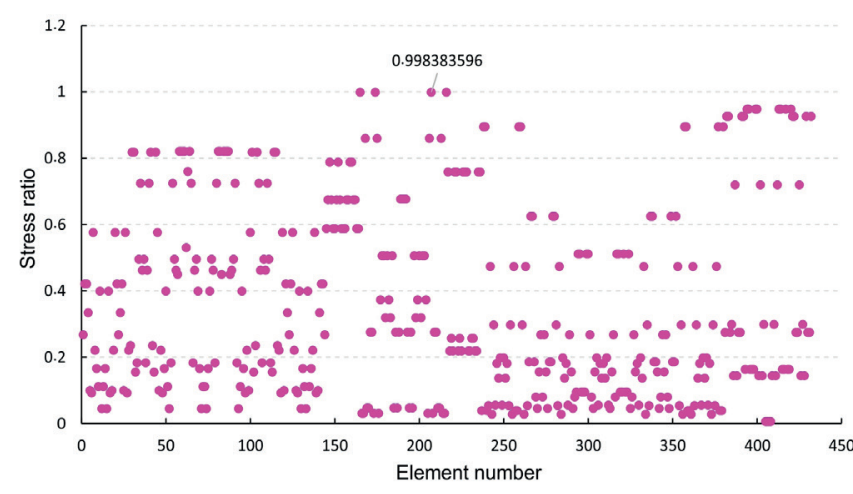

(b)

Fig. 16 The stress ratios for the best design of $12 \mathrm{~m} \times 12 \mathrm{~m}$ square on larger square double-layer grids (a) Two-way on larger two-way grid (b) Diagonal on larger diagonal grid

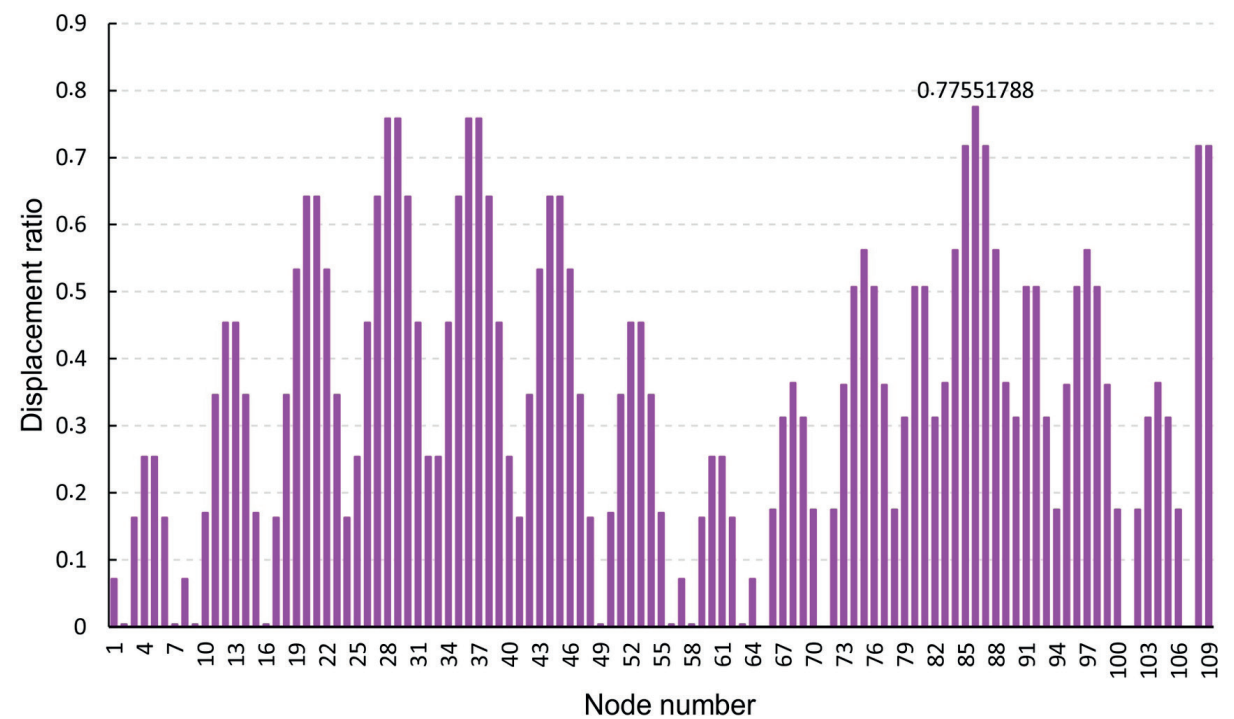

(a)

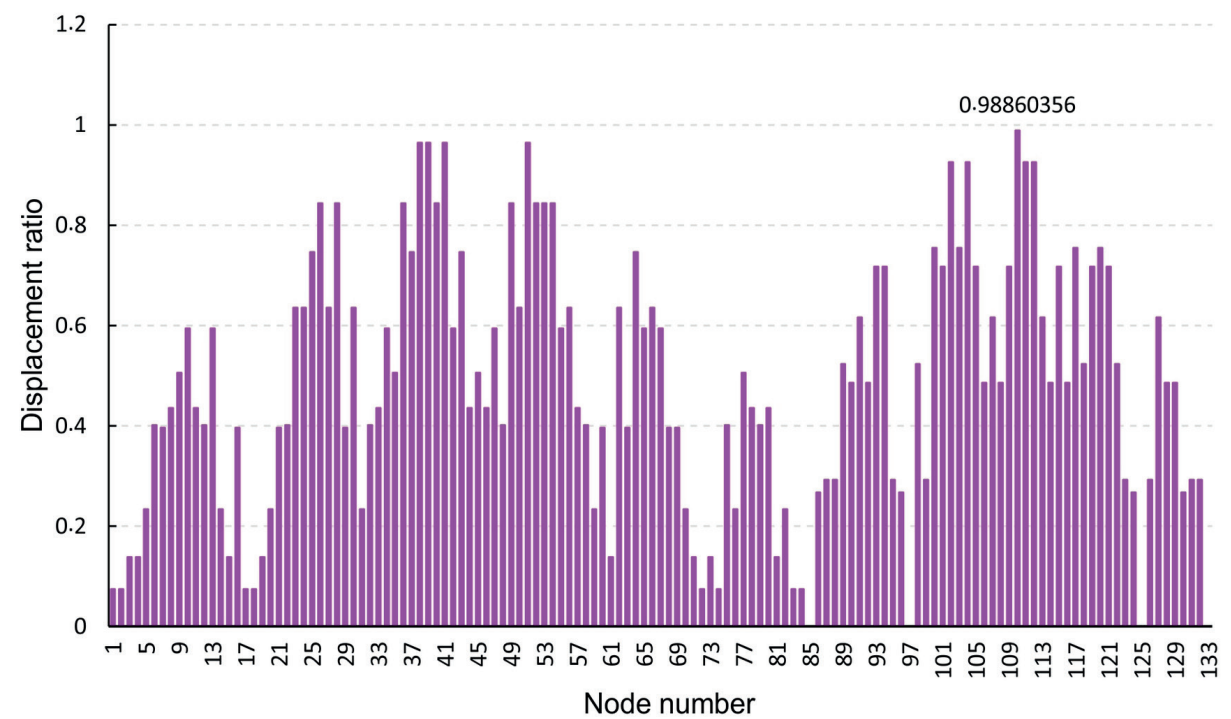

(b)

Fig. 17 The displacement ratios for the best design of $12 \mathrm{~m} \times 12 \mathrm{~m}$ square on larger square double-layer grids (a) Two-way on larger two-way grid (b) Diagonal on larger diagonal grid 
by ECBO, respectively. The maximum stress ratios are $99.86 \%$ and $98.88 \%$ while the maximum displacement ratios are $96.91 \%$ and $99.26 \%$ for the two-way on twoway and diagonal on diagonal grids, respectively.

\section{Discussions and conclusions}

The configuration of the double-layer grids is a significant factor to be scheduled, which affects both the bearing capacity and the weight of the structure. The depth between the top and bottom layers has a noticeable effect upon it. Optimization of large-scale structures with numerous design variables is known as one of the difficult and complex optimization problems, especially when considering the nonlinearity. In this paper, simultaneous shape and size

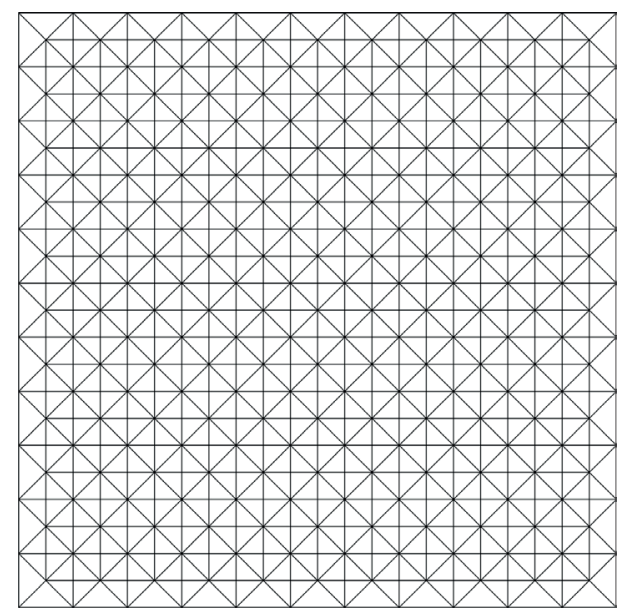

(a)

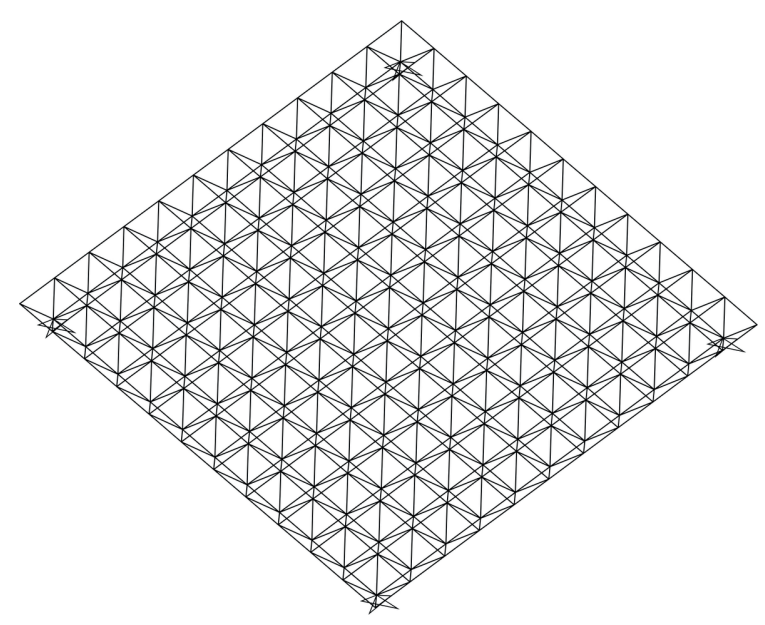

(b)

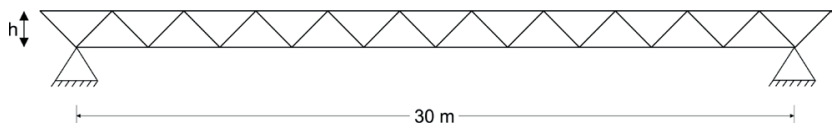

(c)

Fig. 18 Schematic of a $30 \mathrm{~m} \times 30 \mathrm{~m}$ two-way on two-way grid

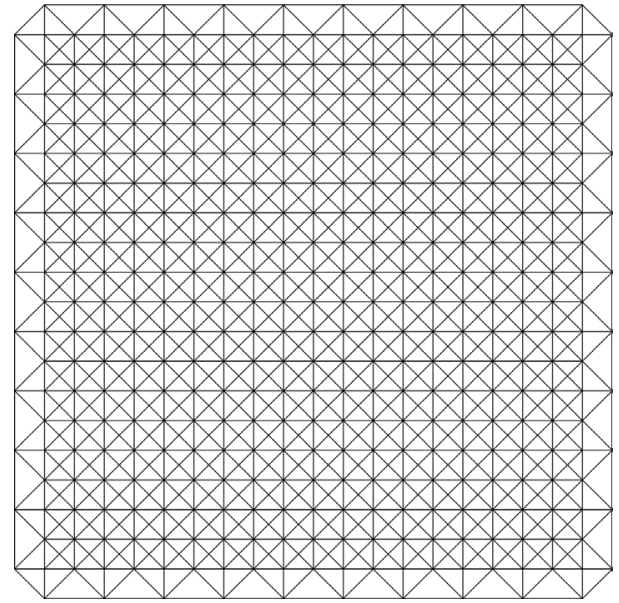

(a)

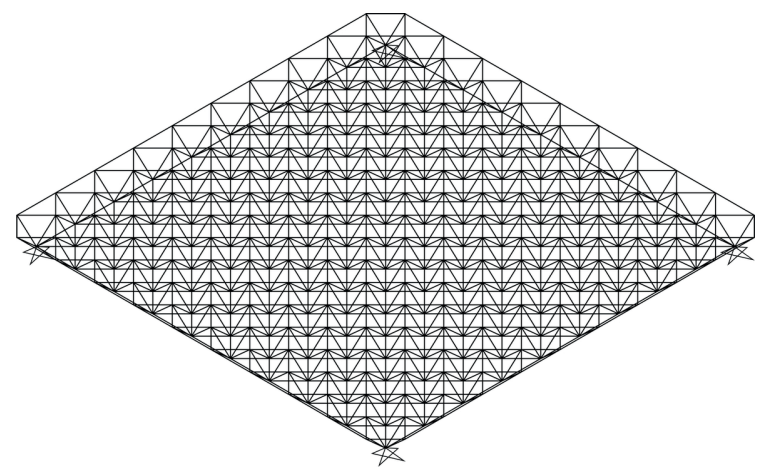

(b)

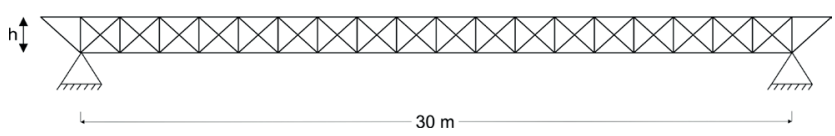

(c)

Fig. 19 Schematic of a $30 \mathrm{~m} \times 30 \mathrm{~m}$ diagonal on diagonal grid

optimization of two-way on two-way, diagonal on diagonal, two-way on larger two-way and diagonal on larger diagonal double-layer grids with different span length as small and large sizes using ECBO algorithm are examined. These grids are subject to the strength and stability constraints of the AISC-LRFD specifications and the displacement limitations. Firstly, a comparative study of two double-layer grids of different sizes and configurations is performed. Results show that simultaneous shape and size optimization has a considerable impact on the weight of the structure and the optimum height can achieve greater relative stiffness for the grids. Varying the length of the diagonal members leads to substantial reduction in the deflections. Secondly, six numerical examples are investigated. In all examples, during the optimization process, both material and geometrical nonlinearity effects are considered. In all the cases, diagonal on diagonal grid with more 


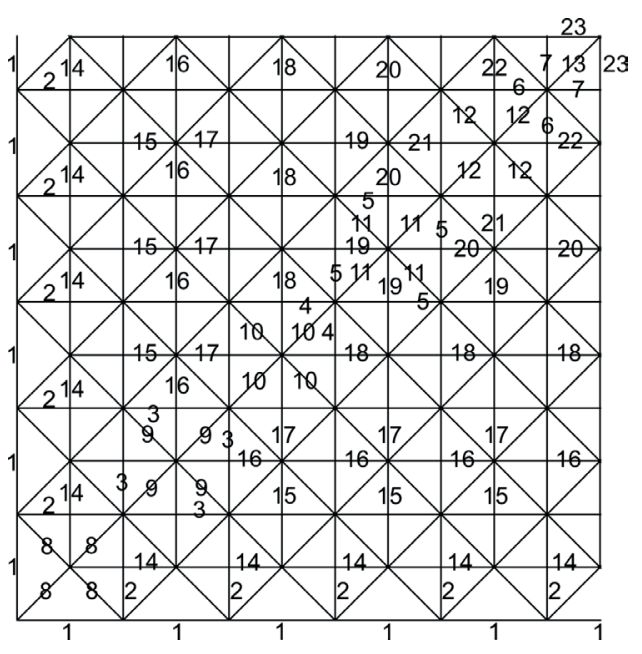

(a)

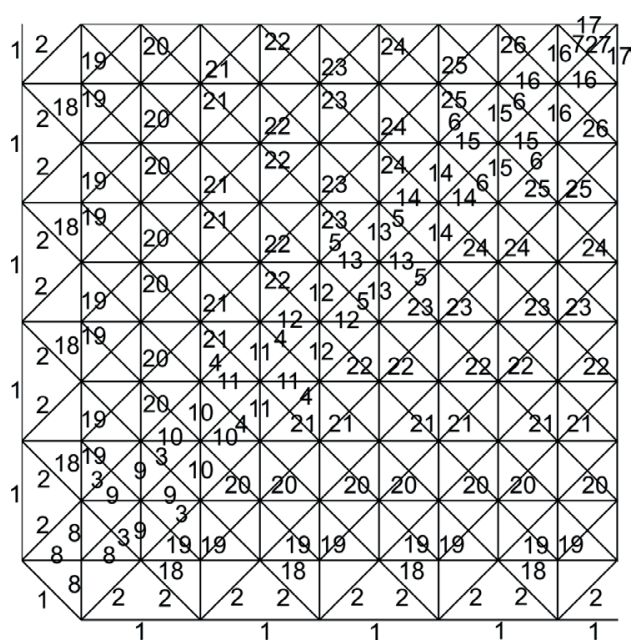

(b)

Fig. 20 Element grouping of the $30 \mathrm{~m} \times 30 \mathrm{~m}$ (a) Two-way on two-way grid, (b) Diagonal on diagonal grid

connections and members results in heavier design than those of other grids. It is worthwhile to mention that if the depth between the top and bottom layer is flexible to choose diagonal on diagonal grid is also a suitable form for covering small span cases because of its greater rigidity, convenience and appealing features. The square on larger square and square on square grids have the lightest designs. The results of applying examples clearly indicate that the proposed approach is an efficient and robust tool for designing large-scale problems and performs well at finding the optimum height of double-layer grids. This method has superiority compared to the other time-consuming methods in terms of reliability and solution accuracy.

For the spans larger than $100 \mathrm{~m}$ it is necessary to incorporate triple-layer grids to avoid long members. Future studies can deal with the design of triple-layer grids
Table 8 Optimal design of the $30 \mathrm{~m} \times 30 \mathrm{~m}$ double-layer grids via ECBO algorithm

\begin{tabular}{|c|c|c|c|}
\hline & & Optimum sec & (designations) \\
\hline & Design Variables & Two-way on & Diagonal on \\
\hline 1 & A1 & EST (4) & $\operatorname{EST}(4)$ \\
\hline 2 & A2 & ST (1) & $\operatorname{EST}\left(\begin{array}{ll}1 & 1 / 2\end{array}\right)$ \\
\hline 3 & A3 & ST (4) & $\operatorname{ST}\left(3 \frac{1}{2}\right)$ \\
\hline 4 & A4 & $\operatorname{EST}\left(2 \frac{1}{2}\right)$ & ST $\left(3 \frac{1}{2}\right)$ \\
\hline 5 & A5 & ST $(31 / 2)$ & $\mathrm{ST}(5)$ \\
\hline 6 & A6 & EST (3) & $\mathrm{ST}(6)$ \\
\hline 7 & A7 & $\mathrm{ST}(5)$ & $\mathrm{ST}(10)$ \\
\hline 8 & A8 & ST (5) & $\operatorname{EST}\left(3 \frac{1}{2}\right)$ \\
\hline 9 & A9 & $\operatorname{EST}\left(3 \frac{1}{2}\right)$ & ST $(21 / 2)$ \\
\hline 10 & A10 & ST $(21 / 2)$ & ST (2) \\
\hline 11 & A11 & ST (2) & ST (2) \\
\hline 12 & A12 & ST (2) & ST $\left(\begin{array}{ll}1 & 1 / 2\end{array}\right)$ \\
\hline 13 & A13 & EST (2) & $\operatorname{EST}\left(1 \frac{1}{2}\right)$ \\
\hline 14 & A14 & ST (5) & ST (2) \\
\hline 15 & A15 & ST (2) & ST (2) \\
\hline 16 & A16 & ST (1) & $\operatorname{EST}\left(1 \frac{1}{2}\right)$ \\
\hline 17 & A17 & EST (2) & ST $\left(3 \frac{1}{2}\right)$ \\
\hline 18 & A18 & ST (3) & ST (6) \\
\hline 19 & A19 & ST $\left(1 \frac{1}{4}\right)$ & ST (4) \\
\hline 20 & A 20 & ST $\left(1 \frac{1}{2}\right)$ & ST $(21 / 2)$ \\
\hline 21 & A21 & ST $\left(2 \frac{1}{2}\right)$ & $\mathrm{ST}\left(2_{1 / 2}\right)$ \\
\hline 22 & A 22 & ST $(21 / 2)$ & $\operatorname{EST}\left(1 \frac{1}{2}\right)$ \\
\hline 23 & A23 & EST (4) & ST $(21 / 2)$ \\
\hline 24 & A24 & N/A & EST (2) \\
\hline 25 & A 25 & N/A & ST (3) \\
\hline 26 & A26 & N/A & EST (2) \\
\hline 27 & A27 & N/A & ST (3) \\
\hline 28 & Optimum Height (m) & 2.65 & 2.4 \\
\hline $\mathrm{Ma}$ & Stress Ratio & 0.9986 & 0.9888 \\
\hline $\mathrm{Ma}$ & Displacement Ratio & 0.9691 & 0.9926 \\
\hline Bes & Weight (kg) & 41904.34 & 45796.86 \\
\hline
\end{tabular}

utilizing the proposed method while challenging newly developed metaheuristic algorithms. Also, different types of connections can be considered and compared during the optimization process. The future work can also utilize optimal analysis and swift analysis for optimal design of double layer grid using symmetry and regularity of these structures, Kaveh [26] and Kaveh et al. [27].

\section{Conflict of Interest}

Kaveh and co-authors have no conflict of interest. 


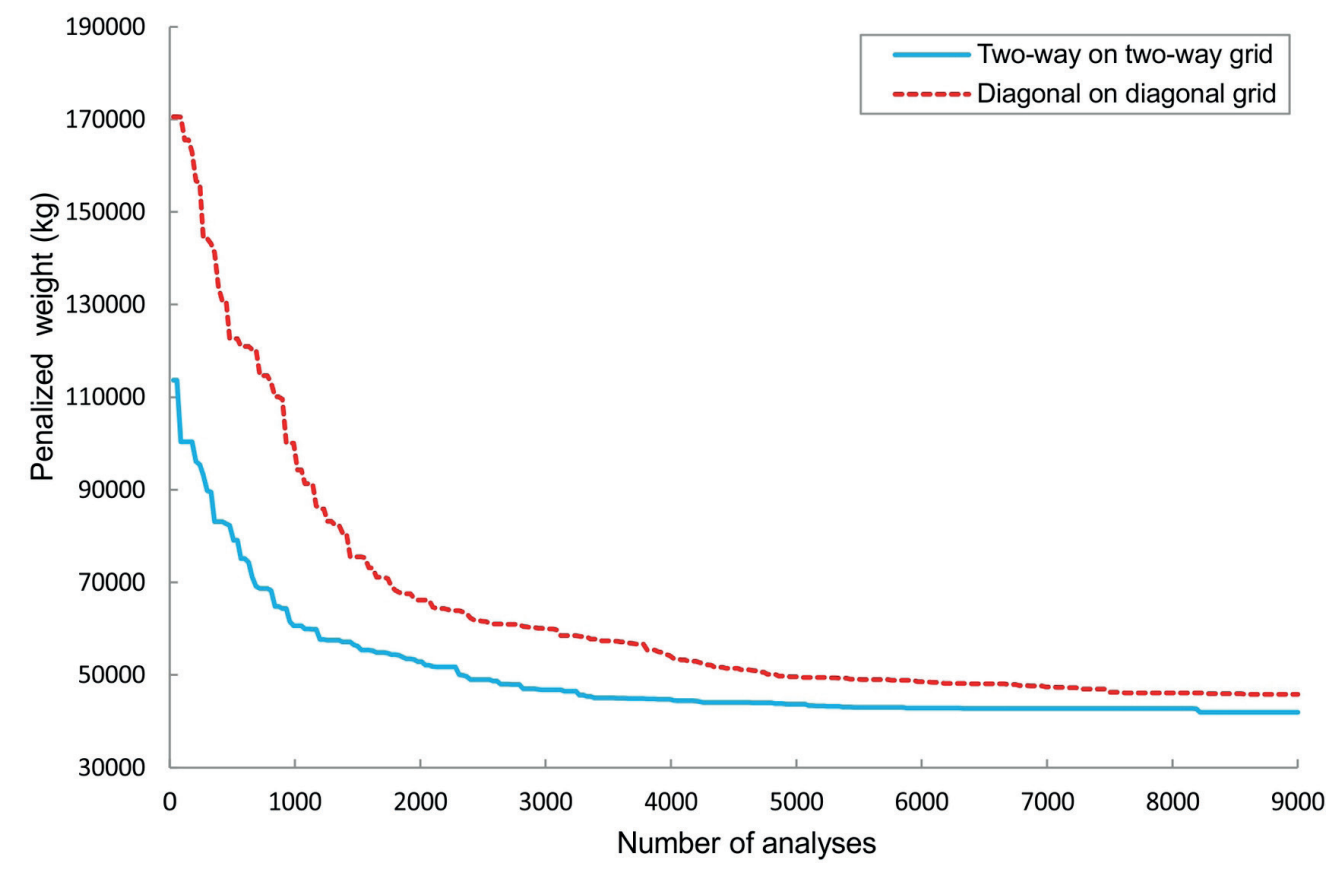

Fig. 21 Convergence curves for the $30 \mathrm{~m} \times 30 \mathrm{~m}$ double-layer grids

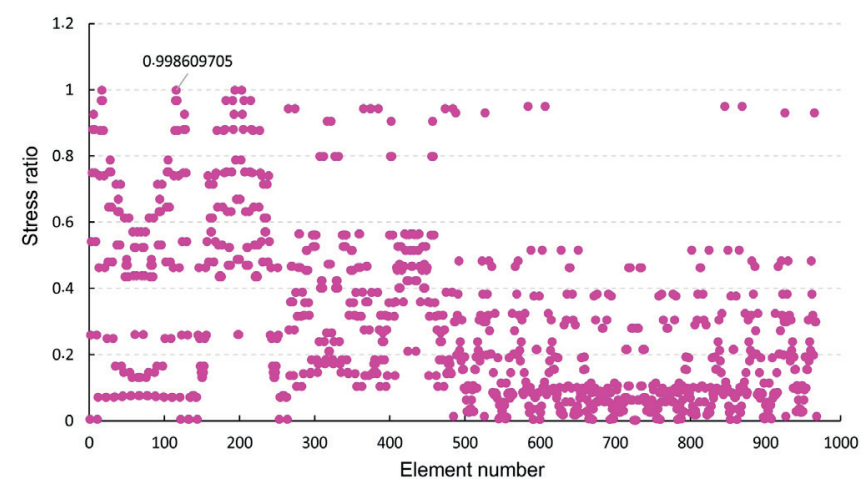

(a)

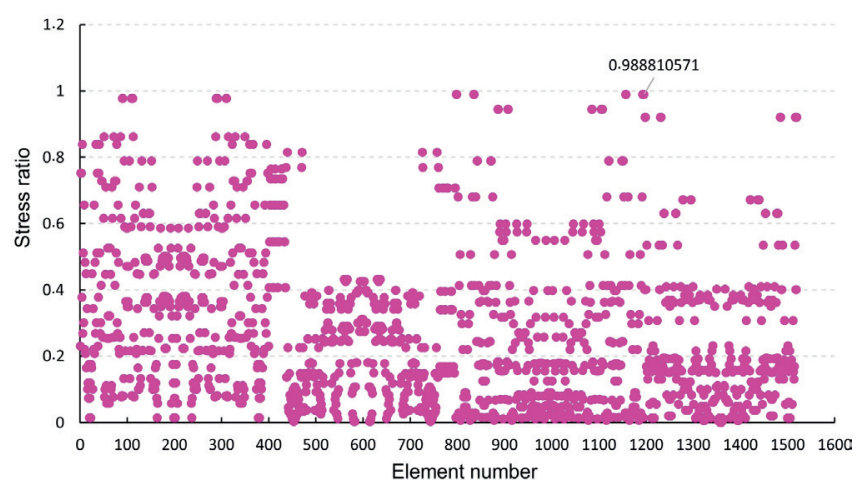

(b)

Fig. 22 The stress ratios for the best design of $30 \mathrm{~m} \times 30 \mathrm{~m}$ double-layer grids (a) Two-way on two-way grid (b) Diagonal on diagonal grid

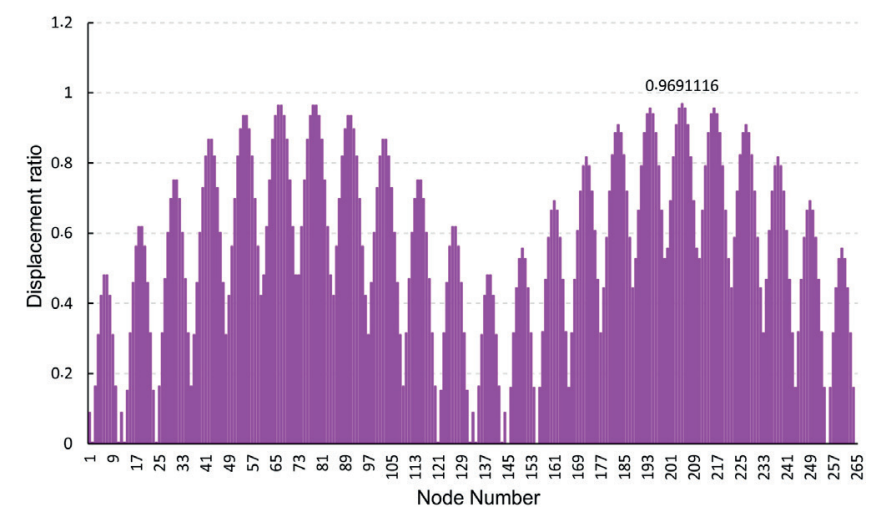

(a)

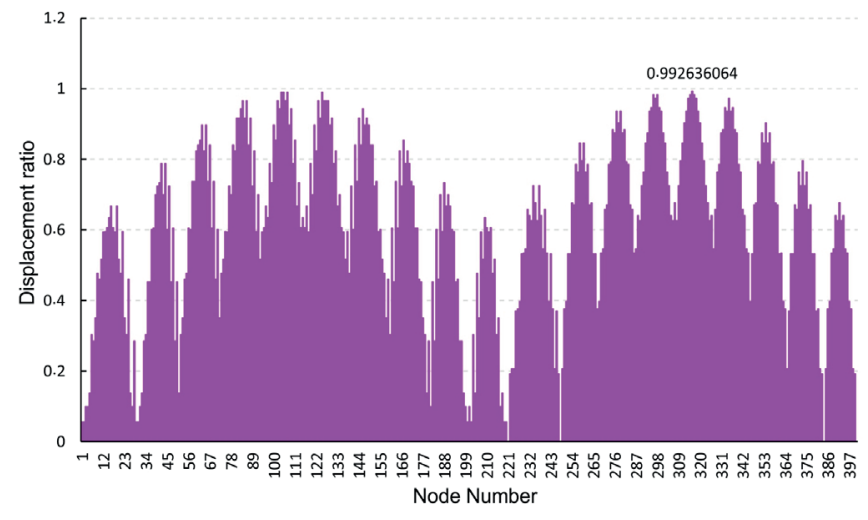

(b)

Fig. 23 The displacement ratios for the best design of $30 \mathrm{~m} \times 30 \mathrm{~m}$ double-layer grids (a) Two-way on two-way grid (b) Diagonal on diagonal grid 


\section{References}

[1] Makowski, Z. S. "Analysis, design and construction of double-layer grids", Halsted Press Division Wiley, New York, NY, USA, 1981.

[2] Hanaor, A., Marsh, C., Parke, G. A. R. "Modification of Behavior of Double-Layer Grids; Overview", Journal of Structural Division, 115(5), pp. 1021-1037, 1989.

https://doi.org/10.1061/(ASCE)0733-9445(1989)115:5(1021)

[3] Alpatov, V. "Creation of mathematical model optimization of Freeform Double-Layer Grids for use in the software package", In: 13th International Conference Modern Building Materials, Structures And Techniques, Vilnius, Lithuania, 2019, pp. 714-721. https://doi.org/10.3846/mbmst.2019.147

[4] Kaveh, A. "Applications of Metaheuristic Optimization Algorithms in Civil Engineering", 2nd ed., Springer, Cham, Switzerland, 2017. https://doi.org/10.1007/978-3-319-48012-1

[5] Chinese Academy of Building Research "Specifications for the design and construction of space trusses (JGJ7-1980)", International Journal of Space Structure, 16(3), pp. 177-208, 2001. https://doi.org/10.1260/0266351011495296

[6] Chen, W.-F., Lui, E. M. "Handbook of Structural Engineering", 2nd ed., CRC Press, Boca Raton, FL, USA, 2005. https://doi.org/10.1201/9781420039931

[7] Kaveh, A., Ilchi Ghazaan, M. "Meta-heuristic Algorithms for Optimal Design of Real-Size Structures", Springer, Cham, Switzerland, 2018.

https://doi.org/10.1007/978-3-319-78780-0

[8] Ermopoulos, J. Ch. "The optimum height design of double-layer grids at the stage of preliminary design", Journal of Constructional Steel Research, 4(4), pp. 281-293, 1984. https://doi.org/10.1016/0143-974X(84)90003-8

[9] Kaveh, A., Talatahari, S. "Size optimization of space trusses using Big Bang-Big Crunch algorithm", Computers and Structures, 87(17-18), pp. 1129-1140, 2009. https://doi.org/10.1016/j.compstruc.2009.04.011

[10] Kaveh, A., Bakhshpoori, T., Afshari, E. "An optimization-based comparative study of double layer grids with two different configurations using cuckoo search algorithm", International Journal of Optimization in Civil Engneering, 1(4), pp. 507-520, 2011. [online] Available at: http://ijoce.iust.ac.ir/article-1-60-en.html

[11] Kaveh, A., Moradveisi, M. "Size and Geometry Optimization of Double-Layer Grids Using CBO and ECBO Algorithms", Iranian Journal of Science and Technology, Transaction of Civil Engineering, 41, pp. 101-112, 2017. https://doi.org/10.1007/s40996-016-0043-y

[12] Kaveh, A., Bakhshpoori, T. "Metaheuristics: Outlines, MATLAB Codes and Examples", Springer, Cham, Switzerland, 2019. https://doi.org/10.1007/978-3-030-04067-3

[13] Kazemzadeh Azad, S., Hasançebi, O., Saka, M. P. "Guided stochastic search technique for discrete sizing optimization of steel trusses: A design-driven heuristic approach", Computers and Structures, 134, pp. 62-74, 2014. https://doi.org/10.1016/j.compstruc.2014.01.005
[14] Kaveh, A., Moradveisi, M. "Nonlinear analysis based optimal design of double-layer grids using enhanced colliding bodies optimization method", Structural Engineering and Mechanics, 58(3), pp. 555-576, 2016. https://doi.org/10.12989/sem.2016.58.3.555

[15] Kaveh, A., Zaerreza, A., Hosseini, S. M. "Shuffled Shepherd Optimization Method Simplified for Reducing the Parameter Dependency", Iranian Journal of Science and Technology, Transaction of Civil Engineering, 2020. https://doi.org/10.1007/s40996-020-00428-3

[16] AISC Manual Committee "Manual of steel construction: Load resistance factor design", AISC, Chicago, IL, USA, 1994.

[17] Kaveh, A., Mahdavi, V. R. "Colliding bodies optimization: A novel meta-heuristic method", Computers and Structures, 139, pp. 18-27, 2014.

https://doi.org/10.1016/j.compstruc.2014.04.005

[18] Kaveh, A., Ilchi Ghazaan, M. "Enhanced colliding bodies optimization for design problems with continuous and discrete variables", Advances in Engineering Software, 77, pp. 66-75, 2014. https://doi.org/10.1016/j.advengsoft.2014.08.003

[19] Kaveh, A., Ilchi Ghazaan, M. "A comparative study of CBO and ECBO for optimal design of skeletal structures", Computers and Structures, 153, pp. 137-147, 2015. https://doi.org/10.1016/j.compstruc.2015.02.028

[20] Ebadi Jamkhaneh, M., Homaioon Ebrahimi, A., Shokri Amiri, M. "Numerical Investigation of the Behavior of MERO Joint System Under Combined Loading Regarding Helical Threads of Elements", International Journal of Steel Structures, 20(3), pp. 897-909, 2020. https://doi.org/10.1007/s13296-020-00330-8

[21] Saka, M. P., Ulker, M. "Optimum design of geometrically nonlinear space trusses", Computers and Structures, 41(6), pp. 13871396, 1991. https://doi.org/10.1016/0045-7949(91)90276-R

[22] Kamyab Moghdas, R., Salajegheh, E. "Size optimization of nonlinear scallop domes by an enhanced particle swarm algorithm", International Journal of Civil Engineering, 11(2), pp. 77-89, 2013. [online] Available at: http://ijce.iust.ac.ir/article-1-731-en.html

[23] Pacific Earthquake Engineering research Center "OpenSees 3.2.0", [computer program] Available at: http://opensees.berkeley.edu

[24] de Borst, R., Crisfield, M. A., Remmers, J. J. C., Verhoosel, C. V. "Non-Linear Finite Element Analysis of Solids and Structures", 2nd ed., John Wiley \& Sons, New York, NY, USA, 2012. https://doi.org/10.1002/9781118375938

[25] Chen, W.-F., El-Metwally, S. E.-D. E. "Understanding Structural Engineering", CRC Press, Boca Raton, FL, USA, 2011. https://doi.org/10.1201/b10914

[26] Kaveh, A. "Optimal Analysis of Structures by Concepts of Symmetry and Regularity", Springer, Vienna, Austria, 2013. https://doi.org/10.1007/978-3-7091-1565-7

[27] Kaveh, A., Rahami, H., Shojaei, I. "Swift Analysis of Structures Using Graph Theory Methods", Springer, Cham, Switzerland, 2020. https://doi.org/10.1007/978-3-030-45549-1 